\title{
Several genetic polymorphisms interact with overweight/obesity to influence serum lipid levels
}

\author{
Rui-Xing Yin ${ }^{1 *}$, Dong-Feng Wu', Lin Miao', Lynn Htet Htet Aung ${ }^{1}$, Xiao-Li Cao ${ }^{1}$, Ting-Ting Yan ${ }^{1}$, Xing-Jiang Long ${ }^{1}$,
} Wan-Ying Liu', Lin Zhang ${ }^{3}$ and Meng Li'

\begin{abstract}
Background: Information about the interactions of single nucleotide polymorphisms (SNPs) and overweight/ obesity on serum lipid profiles is still scarce. The present study was undertaken to detect ten SNPs and their interactions with overweight/obesity on serum lipid levels.
\end{abstract}

Methods: A total of 978 normal weight and 751 overweight/obese subjects of Bai Ku Yao were randomly selected from our previous stratified randomized cluster samples. Normal weight, overweight and obesity were defined as a body mass index $(\mathrm{BMI})<24,24-28$, and $>28 \mathrm{~kg} / \mathrm{m}^{2}$; respectively. Serum total cholesterol (TC), triglyceride (TG), high-density lipoprotein cholesterol (HDL-C), low-density lipoprotein cholesterol (LDL-C), apolipoprotein (Apo) A1 and ApoB levels were measured. Genotyping of ATP-binding cassette transporter A1 (ABCA-1) V825I, acyl-CoA: cholesterol acyltransferase-1 (ACAT-1) rs 1044925, low density lipoprotein receptor (LDL-R) Avall, hepatic lipase gene (LIPC) -250G >A, endothelial lipase gene (LIPG) 584C >T, methylenetetrahydrofolate reductase (MTHFR) 677C >T, the E3 ubiquitin ligase myosin regulatory light chain-interacting protein (MYLIP) rs3757354, proprotein convertase subtilisin-like kexin type 9 (PCSK9) E670G, peroxisome proliferator-activated receptor delta (PPARD) +294 T >C, and Scavenger receptor class B type 1 (SCARB1) rs5888 was performed by polymerase chain reaction and restriction fragment length polymorphism combined with gel electrophoresis, and then confirmed by direct sequencing. The interactions were detected by factorial design covariance analysis.

Results: The genotypic and allelic frequencies of LIPC and PCSK9 were different between normal weight and overweight/obese subjects, the genotypic frequency of LIPG and allelic frequency of MYLIP were also different between normal weight and overweight/obese subjects $(P<0.05-0.001)$. The levels of TC, ApoA1 (ABCA-1); TC, LDL-C, ApoA1, ApoB and ApoA1/ApoB (LIPC); TG, HDL-C, and ApoA1 (LIPG); TC, HDL-C, LDL-C, ApoA1 and ApoB (MTHFR); HDL-C and ApoA1 (MYLIP) in normal weight subjects were different among the genotypes $(P<0.01-0.001)$. The levels of $L D L-C, A p o B$ and ApoA1/ApoB (ABCA-1); HDL-C, ApoA1, ApoB and ApoA1/ApoB (LIPC); TC, HDL-C, ApoA1 and ApoB (LIPG); TC, TG, HDL-C, LDL-C, ApoA1 and ApoB (MTHFR); TC, TG and ApoB (MYLIP); TG (PCSK9); TG, ApoA1 and ApoB (PPARD); and TC, HDL-C, LDL-C, ApoA1 and ApoB (SCARB1) in overweight/obese subjects were different among the genotypes $(P<0.01-0.001)$. The SNPs of ABCA-1 (LDL-C and ApoA1/ApoB); LIPC (TC, LDL-C, ApoA1 and ApoB); LIPG (ApoB); MTHFR (TC, TG and LDL-C); MYLIP (TC and TG); PCSK9 (TG, HDL-C, ApoB and ApoA1/ApoB); PPARD (TG and ApoA1/ApoB); and SCARB1 (TG, ApoA1 and ApoB) interacted with overweight/obesity to influence serum lipid levels $(P<0.05-0.001)$.

Conclusions: The differences in serum lipid levels between normal weight and overweight/obese subjects might partly result from different genetic polymorphisms and the interactions between several SNPs and overweight/ obesity.

Keywords: Lipid, Apolipoprotein, Genetic polymorphism, Overweight, Obesity, Interaction

\footnotetext{
* Correspondence: yinruixing@yahoo.com.cn

'Department of Cardiology, Institute of Cardiovascular Diseases, the First Affiliated Hospital, Guangxi Medical University, 22 Shuangyong Road,

Nanning, Guangxi 530021, People's Republic of China

Full list of author information is available at the end of the article
} 


\section{Introduction}

Dyslipidemia such as elevated levels of total cholesterol (TC) [1], triglyceride (TG) [2], low-density lipoprotein cholesterol (LDL-C) [3], and apolipoprotein (Apo) B [4], together with decreased levels of ApoA1 [4] and highdensity lipoprotein cholesterol (HDL-C) [5] has become one of the most urgent public health problems in many countries because of its high prevalence and a causal relationship with serious medical condition such as coronary artery disease (CAD), hypertension and stroke [6]. It is well known that dyslipidemia is a complex trait caused by multiple environmental and genetic factors and their interactions [7-12]. The link between overweight/obesity and dyslipidemia has been well documented [13-17]. Obesity is a specific phenotype that may be affected by genetic and environmental factors, involving excessive caloric intake, unhealthy lifestyle, insufficient physical activity, social and economic forces, as well as metabolic and endocrine abnormalities. The increase in body fat, especially the intra-abdominal adipose tissue is a major contributor to the development of dyslipidemia, insulin resistance, and hypertension and is associated with chronic diseases such as type 2 diabetes, CAD, metabolic syndrome, stroke, sleep disorders, osteoarthritis, and increased incidence of certain forms of cancer [17]. The prevalence of obesity has dramatically increased during recent years in all parts of the world [18]. According to the World Health Organization (WHO), more than 400 million adults were obese in 2005, and it is estimated that more than 700 million adults will be obese by 2015 [19]. Moreover, the rates of increase and the overall prevalence of obesity vary greatly across ethnic groups [20]. Among Americans, data from the National Health and Nutrition Examination Survey (NHANES) conducted in 2007-2008 showed that adults of 32.8\% of non-Hispanic whites, $44.1 \%$ of non-Hispanic blacks, and $39.3 \%$ of Mexican-Americans were either overweight or obese [21]. The prevalence of overweight and obesity in Chinese was $24.1 \%$ and $2.8 \%$ in men and $26.1 \%$ and $5.0 \%$ in women; respectively. The prevalence of central obesity was $16.1 \%$ in men and $37.6 \%$ in women. The prevalences of overweight, obesity, and central obesity were higher among residents in northern China compared with their counterparts in southern China and among those in urban areas compared with those in rural areas [22]. Obesity has become a major clinical and public health problem that threatens to overwhelm already extended healthcare services in many countries. Genetic influences on lipid traits have been suggested by numerous studies. Recent large-scale genome-wide association studies in multiple populations have identified more than 95 loci associated with serum lipid levels [23]. Common variants at these loci together explain $<10 \%$ of variation in each lipid trait [24-26]. Rare variants with large individual effects may also contribute to the heritability of lipid traits [26]. But the results of these association studies conducted with blood lipid traits are inconsistent in diverse racial/ethnic groups. A major reason for inconsistency among studies may be different environmental modifiers that interact with genes to influence serum lipid levels.

China is a multiethnic country with 56 ethnic groups. Han nationality is the largest ethnic group, and Yao nationality is the eleventh largest minority among the $55 \mathrm{mi}-$ nority groups according to the population size. Bai Ku Yao (White-trouser Yao), an isolated subgroup of the Yao minority, is named so because all of men wear white kneelength knickerbockers. The population size is about 30 000. Because of isolation from the other ethnic groups, the special customs and cultures including their clothing, intra-ethnic marriages, dietary patterns, and corn wine and rum intakes are still completely preserved to the present day. Thus, this ethnic subgroup is thought to share the same ethnic ancestry and to possess a homogeneous genetic background. Bai Ku Yao has become a useful subgroup for population genetic studies. In previous epidemiological studies, we found that the prevalence of dyslipidemia was lower in normal weight than in overweight/obese subjects [7-9]. We hypothesized that the differences in serum lipid levels between normal weight and overweight/obese subjects might partly result from different interactions of some single nucleotide polymorphisms (SNPs) and overweight/obesity in this population. Therefore, the purpose of this study was to detect ten SNPs in different genes and evaluate their interactions with overweight/obesity on serum lipid levels in the Guangxi Bai $\mathrm{Ku}$ Yao population. The SNPs were selected according to the previous findings of genome-wide association studies [23-26] and bioinformatics functional assessment. Computational analysis of ten SNPs ascribed potential functional characteristics to each variant allele. In addition, the ten SNPs selected for genotyping also based on the frequency of Beijing Han population from the Human Genome Project Database. The heterozygosity values were higher than $10 \%$ for the minor allele frequency. These SNPs have been associated with serum lipid profiles in the Bai Ku Yao population [27-35].

\section{Methods}

\section{Study population}

The study population consisted of 1729 unrelated participants of Bai $\mathrm{Ku}$ Yao who reside in Lihu and Baxu villages in Nandan County, Guangxi Zhuang Autonomous Region, People's Republic of China. They were randomly selected from our previous stratified randomized cluster samples [7-9]. The age of the subjects ranged from 15 to 86 years, with an average age of $41.38 \pm 14.71$ years. There were 978 normal weight subjects (490 males and 
488 females) and 751 overweight/obese subjects (378 men and 373 women). All of the subjects were rural agricultural workers. The subjects had no evidence of diseases related to atherosclerosis, CAD and diabetes. The participants were not taking medications known to affect serum lipid levels (lipid-lowering drugs such as statins or fibrates, beta-blockers, diuretics, hormones, or contraceptive drugs). The protocol was approved by the Ethics Committee of the First Affiliated Hospital, Guangxi Medical University. Written informed consent was obtained from each participant.

\section{Epidemiological survey}

The survey was done according to standardized methods [7-9]. Questionnaires were administered to assess demographic information, socioeconomic status, lifestyle factors, and medical and medication history. Blood pressure was measured three times by a well trained physician with the use of a standard mercury sphygmomanometer while subjects were seated and had rested for $5 \mathrm{~min}$. Systolic and diastolic blood pressure values were the mean of three measurements. Systolic blood pressure was determined by the first Korotkoff sound, and diastolic blood pressure by the fifth Korotkoff sound. Pulse pressure was calculated as the systolic minus the diastolic blood pressure. Weight was measured with a beam balance and height with a fixed stadiometer. Subjects were measured without shoes and in a minimum of clothing. Body mass index (BMI) was calculated as weight in kilograms divided by the square of height in meters. Waist circumference was measured at the umbilicus.

\section{Biochemical measurements}

Fasting venous blood samples of $5 \mathrm{~mL}$ were obtained from all subjects. A part of the sample $(2 \mathrm{~mL})$ was collected into glass tubes and used to determine serum lipid levels. Another part of the sample $(3 \mathrm{~mL})$ was transferred to tubes with anticoagulate solution and used to extract deoxyribonucleic acid (DNA). The levels of TC, TG, HDL-C, and LDL-C in samples were determined by enzymatic methods. Serum ApoA1 and ApoB levels were detected by the immunoturbidimetric immunoassay. All determinations were performed with an autoanalyzer (Type 7170A; Hitachi Ltd., Tokyo, Japan) in our Clinical Science Experiment Center [7-9].

\section{Genetic analyses}

Genomic DNA was extracted from the peripheral blood leukocytes by the phenol-chloroform method as our previous reports [27-35]. Genotyping of ATP-binding cassette transporter A1 (ABCA-1) V825I (rs2066715), acyl-CoA: cholesterol acyltransferase-1 (ACAT-1) rs1044925, low density lipoprotein receptor (LDL-R) AvaII, hepatic lipase gene (LIPC) -250G>A (rs2070895), endothelial lipase gene
(LIPG) 584C $>\mathrm{T}$ (rs2000813), methylenetetrahydrofolate reductase (MTHFR) 677C $>\mathrm{T}$ (rs1801133), the E3 ubiquitin ligase myosin regulatory light chain-interacting protein (MYLIP, also known as IDOL) rs3757354, proprotein convertase subtilisin-like kexin type 9 (PCSK9) E670G (rs505151), peroxisome proliferator-activated receptor delta (PPARD) +294T>C (rs2016520) and Scavenger receptor class B type 1 (SCARB1) rs5888 was performed using polymerase chain reaction and restriction fragment length polymorphism (PCR-RFLP). The sequences of the forward and reverse primers and restriction ezyme used for the genotyping of ten SNPs are list in Table 1. The thermocycling protocol, the approach to electrophoresis, and the procedures for quality control have been described previously [27-35]. Genotypes were scored by an experienced reader blinded to epidemiological data and serum lipid levels.

\section{DNA sequencing}

Fifty-eight samples (each genotype in two; respectively) detected by the PCR-RFLP were also confirmed by direct sequencing. The PCR products were purified by low melting point gel electrophoresis and phenol extraction, and then the DNA sequences were analyzed in Shanghai Sangon Biological Engineering Technology \& Services Co., Ltd., People's Republic of China.

\section{Diagnostic criteria}

The normal values of serum TC, TG, HDL-C, LDL-C, ApoA1, ApoB levels and the ratio of ApoA1 to ApoB in our Clinical Science Experiment Center were 3.10-5.17, $0.56-1.70,1.16-1.42,2.70-3.10 \mathrm{mmol} / \mathrm{L}, 1.20-1.60,0.80-$ $1.05 \mathrm{~g} / \mathrm{L}$, and 1.00-2.50; respectively. The individuals with $\mathrm{TC}>5.17 \mathrm{mmol} / \mathrm{L}$ and/or $\mathrm{TG}>1.70 \mathrm{mmol} / \mathrm{L}$ were defined as hyperlipidemic [7-9]. The diagnostic criteria of overweight and obesity were according to the Cooperative Meta-analysis Group of China Obesity Task Force. Normal weight, overweight and obesity were defined as a BMI $<24,24-28$, and $>28 \mathrm{~kg} / \mathrm{m}^{2}$; respectively $[14,36]$.

\section{Statistical analysis}

Data are presented as means \pm SD for continuous variables and as frequencies or percentages for categorical variables. Chi square tests were used to compare the differences in percentages and to assess Hardy-Weinberg expectations. Differences in mean values were assessed using analysis of covariance (ANCOVA) and unpaired $t$ tests. Potential confounding factors were sex, age, education level, physical activity, blood pressure, alcohol consumption, and cigarette smoking. All significant associations were further corrected for multiple tests by a permutation test. The permutation test was conducted by changing the orders of dependant variable randomly against the genotypes (under the null hypothesis - no 
Table 1 The sequences of forward (F) and reverse (R) primers and restriction enzymes for genotyping of the ten SNPs

\begin{tabular}{|c|c|c|c|c|}
\hline SNP & Primer sequence & Restriction enzyme & PCR product & Allele \\
\hline$A B C A-1$ V825I & F: 5/-GGTAGCCCACCACTCTCCCCTATAAAG-3/ & Tagl & $525 \mathrm{bp}$ & G \\
\hline (rs2066715) & R: 5/-ATCAGCTGCCTGTCCTTGGACTA-3/ & & & A \\
\hline ACAT-1 & F: 5/-TATATTAAGGGGATCAGAAGT-3/ & Rsal & $389 \mathrm{bp}$ & A \\
\hline (rs1044925) & R: 5/-CCACCTAAAAACATACTACC-31 & & & C \\
\hline \multirow[t]{2}{*}{ LDL-R Avall } & F: 5/-GTCATCTTCCTTGCTGCCTGTTTAG-3I & Avall & $228 \mathrm{bp}$ & A- \\
\hline & R: 5/-GTTTCCACAAGGAGGTTTCAAGGTT-31 & & & A+ \\
\hline LIPC $-250 G>A$ & F: 5/-GGCAAGGGCATCTITGCTTC-3I & Dral & 411-bp & G \\
\hline (rs2070895) & R: 5/-GGTCGATTTACAGAAGTGCTTC-31 & & & A \\
\hline LIPG 584C>T & F: 5/-CATGAGCTGAGATTGTTGTCAGTGC-31 & Ndel & $254 \mathrm{bp}$ & C \\
\hline (rs2000813) & R: 5/-CAGTCAACCACAACTACATTGGCGTCTTTCTCTCAT-3/ & & & $\mathrm{T}$ \\
\hline MTHFR $677 C>T$ & F: 5/-CAAAGGCCACCCCGAAGC-3/ & Hinfl & $254 \mathrm{bp}$ & C \\
\hline (rs1801133) & R: 5/-AGGACGGTGCGGTGAGAGTG-31 & & & $\mathrm{T}$ \\
\hline MYLIP & F: 5/-ACAGAGCAAAAGACCCTGTCTC-3' & Haelll & $387 \mathrm{bp}$ & G \\
\hline (rs3757354) & R: 5/-AAAGAACTGTGTGTGGGAGGAT-3/ & & & $\mathrm{T}$ \\
\hline PCSK9 E670G & F: 5/-CACGGTTGTGTCCCAAATGG-3I & Eam 11041 & $440 \mathrm{bp}$ & A \\
\hline$($ rs505151) & R: 5/-GAGAGGGACAAGTCGGAACC-31 & & & G \\
\hline PPARD +294 T $>C$ & F: 5/-CATGGTATAGCACTGCAGGAA-3I & $B s \|$ & $269 \mathrm{bp}$ & $\mathrm{T}$ \\
\hline (rs2016520) & R: 5/-CTTCCTCCTGTGGCTGCTC-3ı & & & $\mathrm{C}$ \\
\hline SCARB1 & F: 5/-CCTTGTTTCTCTCCCATCCTCACTTCCTCGACGC-3/ & Hinl1 & $218 \mathrm{bp}$ & $\mathrm{C}$ \\
\hline$($ (rs5888) & R: 5/-CACCACCCCAGCCCACAGCAGC-31 & & & $\mathrm{T}$ \\
\hline
\end{tabular}

association between dependant variable and haplotypes). This process was repeated 1000 times. The $P$ values of 1000 permutations were sorted in a descending manner. If the observed $P$ value is less than or equal to the $950^{\text {th }} P$ value, the association was considered statistically significant. The allelic and genotypic frequencies were calculated from the observed genotypic counts. The interactions of ten SNPs and overweight/obesity on serum lipid levels were assessed by using a factorial design covariance analysis after controlling for potential confounders. Multiple linear regression was used to ascertain the correlation between genotypes (ABCA-1: $\mathrm{GG}=1, \mathrm{GA}=2, \mathrm{AA}=3$; ACAT-1: $\mathrm{AA}=1, \mathrm{AC}=2, \mathrm{CC}=3$; LDL-R: A-A- = 1, A-A+ $=2, \mathrm{~A}+\mathrm{A}+=3$; LIPC: $\mathrm{GG}=1, \mathrm{GA}=2, \mathrm{AA}=3$; LIPG: $\mathrm{CC}$ $=1, \mathrm{CT}=2, \mathrm{TT}=3$; MTHFR: $\mathrm{CC}=1, \mathrm{CT}=2, \mathrm{TT}=3$; MYLIP: $\mathrm{AA}=1, \mathrm{AG}=2, \mathrm{GG}=3$; PCSK9: $\mathrm{AA}=1, \mathrm{AG}=2$; PPARD: $\mathrm{TT}=1, \mathrm{TC}=2, \mathrm{CC}=3$; and SCARB1: $\mathrm{CC}=1$, $\mathrm{CT}=2$, $\mathrm{TT}=3$ ) or alleles (the minor allele noncarrier $=1$, the minor allele carrier $=2$ ) and serum lipid parameters in the combined population of normal weight and overweight/obese subjects, normal weight subjects, and overweight/obese subjects; respectively.

\section{Results}

\section{General characteristics}

Table 2 shows the general characteristics of the participants. The levels of education, weight, BMI, waist circumference, systolic blood pressure, diastolic blood pressure, serum TC, TG, LDL-C, ApoA1, ApoB, and the percentages of subjects who consumed alcohol were higher in overweight/obese than in normal weight subjects $(P<0.05-0.001)$, whereas the levels of serum HDL-C, the ratio of ApoA1 to ApoB, and the percentages of subjects who smoked cigarettes were lower in overweight/obese than in normal weight subjects $(P<0.01$ for all $)$. There were no significant differences in the levels of mean age, height, pulse pressure, and the ratio of male to female between the overweight/obese and normal weight subjects $(P>$ 0.05 for all).

\section{Electrophoresis and genotypes}

The PCR products of ABCA-1, ACAT-1, LDL-R, LIPC, LIPG, MTHFR, MYLIP, PCSK9, PPARD, and SCARB1 SNPs were 525-, 389-, 228-, 411-, 254-, 254-, 387-, 440-, 269- and 218-bp nucleotide sequences; respectively. The genotypes identified were named according to the presence or absence of the enzyme restriction sites (Figure 1). Lane $\mathrm{M}$ is 50 - or 100 -bp marker ladder. The genotypes of the ten SNPs are as follows: ABCA1, GG (lanes 1 and 2, 525-bp), GA (lanes 3 and 4, 525-, 302- and 223-bp), and AA genotypes (lanes 5 and 6, 302- and 223-bp); ACAT-1, AA (lanes 1-3, 389-bp), AC (lanes 4 and 5, 389-, 279and 110-bp), and CC genotypes (lanes 6 and 7, 279- and 
Table 2 The general characteristics and serum lipid levels between the subjects with normal weight and overweight/ obesity

\begin{tabular}{|c|c|c|c|c|}
\hline Characteristics & Normal weight & Overweight/obesity & $t\left(x^{2}\right)$ & $P$ \\
\hline Number & 978 & 751 & - & - \\
\hline Male/female & $490 / 488$ & $378 / 373$ & 0.009 & 0.924 \\
\hline Age, years & $41.48 \pm 16.21$ & $41.25 \pm 12.50$ & 0.332 & 0.740 \\
\hline Education level, years & $3.71 \pm 3.89$ & $4.71 \pm 4.49$ & -4.170 & 0.000 \\
\hline Height, $\mathrm{cm}$ & $153.73 \pm 7.57$ & $154.29 \pm 8.49$ & -1.461 & 0.144 \\
\hline Weight, kg & $50.28 \pm 6.20$ & $63.19 \pm 8.86$ & -34.042 & 0.000 \\
\hline Body mass index, $\mathrm{kg} / \mathrm{m}^{2}$ & $21.23 \pm 1.68$ & $26.48 \pm 2.59$ & -48.285 & 0.000 \\
\hline Waist circumference, $\mathrm{cm}$ & $70.58 \pm 6.56$ & $82.90 \pm 7.39$ & -30.766 & 0.000 \\
\hline Alcohol consumption, $n(\%)$ & $373(38.1)$ & $362(48.2)$ & 23.034 & 0.000 \\
\hline Cigarette smoking, $n$ (\%) & $305(31.2)$ & $178(23.7)$ & 15.036 & 0.001 \\
\hline Systolic blood pressure, $\mathrm{mmHg}$ & $119.69 \pm 17.40$ & $125.84 \pm 17.64$ & -7.242 & 0.000 \\
\hline Diastolic blood pressure, $\mathrm{mmHg}$ & $75.11 \pm 9.98$ & $80.57 \pm 11.13$ & -10.563 & 0.000 \\
\hline Pulse pressure, $\mathrm{mmHg}$ & $44.60 \pm 12.87$ & $45.36 \pm 12.11$ & -1.251 & 0.211 \\
\hline Total cholesterol, mmol/L & $4.46 \pm 0.94$ & $5.01 \pm 1.05$ & -11.325 & 0.000 \\
\hline Triglyceride, mmol/L & $1.21 \pm 1.02$ & $1.74 \pm 1.50$ & -8.837 & 0.000 \\
\hline $\mathrm{HDL}-\mathrm{C}, \mathrm{mmol} / \mathrm{L}$ & $1.80 \pm 0.47$ & $1.73 \pm 0.41$ & 3.099 & 0.002 \\
\hline $\mathrm{LDL}-\mathrm{C}, \mathrm{mmol} / \mathrm{L}$ & $2.52 \pm 0.73$ & $2.96 \pm 0.85$ & -11.180 & 0.000 \\
\hline Apolipoprotein (Apo) A1, g/L & $1.37 \pm 0.31$ & $1.40 \pm 0.27$ & -2.009 & 0.045 \\
\hline ApoB, g/L & $0.84 \pm 0.22$ & $0.98 \pm 0.24$ & -12.466 & 0.000 \\
\hline ApoA1/ApoB & $1.75 \pm 0.70$ & $1.53 \pm 0.58$ & 7.256 & 0.000 \\
\hline
\end{tabular}

HDL-C, high-density lipoprotein cholesterol; LDL-C, low-density lipoprotein cholesterol.

110-bp); LDL-R, A+A+ (lanes 1-6, 141- and 87-bp), A-A+ (lanes 7-12, 228-, 141- and 87-bp), and A-A- genotypes (lanes 13-15, 228-bp); LIPC, GG (lanes 1-3, 411-bp), GA (lane 4, 411-, 301- and 110-bp), and AA genotypes (lanes 5-7, 301- and 110-bp); LIPG, PCR product of the sample (lane 1, 254-bp), CC (lanes 2 and 3, 254-bp), CT (lanes 4 and 5, 254-, 217- and 37-bp), and TT genotypes (lanes 6 and 7, 217- and 37-bp); MTHFR, CC (lanes 1 and 2, 245bp), CT (lane 3 and 4, 245-, 173- and 72-bp), and TT genotypes (lanes 5 and 6, 173- and 72-bp); MYLIP, AA (lanes 1 and 2, 387-bp), AG (lanes 3 and 4, 387-, 306- and 81bp), and GG genotypes (lanes 5 and 6, 306- and 81-bp); PCSK9, PCR products of the samples (lanes 1 and 2, 440bp), AG (lanes 3 and 4, 440-, 290- and 150-bp), and AA genotypes (lanes 5 and 6, 290- and 150-bp); PPARD, TT (lanes 1 and 2, 269-bp), TC (lanes 3-5, 269-, 167- and 102bp), and CC genotypes (lanes 6 and 7, 167- and 102-bp); and SCARB1, TT (lanes 1 and 2, 218-bp), CT (lanes 3 and 4, 218-, 187- and 31-bp), and CC genotypes (lanes 5 and 6, 187- and 31-bp). The 37-bp fragment of LIPG and 31bp fragment of SCARB1 were invisible in the gel owing to their fast migration speed. The GG homozygous of the PCSK9 E670G was not detected in our study population.

\section{Nucleotide sequences}

The genotypes detected by PCR-RFLP were also confirmed by direct sequencing (Figure 2).

\section{Genotypic and allelic frequencies}

The genotypic and allelic frequencies of the SNPs between normal weight and overweight/obese subjects are summarized in Table 3. The genotypic distribution of ten SNPs was in Hardy-Weinberg equilibrium $(P>0.05$ for all). The genotypic and allelic frequencies of LIPC and PCSK9 were different between normal weight and overweight/obese subjects, the overweight/obese subjects had higher LIPC -250A and PCSK9 670A allele frequencies than normal weight subjects $(P<0.05-0.001)$. The genotypic frequency of LIPG and allelic frequency of MYLIP were also different between normal weight and overweight/obese subjects $(P<0.05$ for each). There were no significant differences in the genotypic and allelic frequencies of the remaining SNPs between normal weight and overweight/obese subjects $(P<0.05$ for all). The GG homozygous of the PCSK9 E670G was not detected in our study population.

\section{Genotypes and serum lipid levels}

The association of genotypes and serum lipid parameters between normal weight and overweight/obese subjects is shown in Figure 3 . The levels of $\mathrm{TC}$, ApoA1 (ABCA-1); TC, LDL-C, ApoA1, ApoB and ApoA1/ApoB (LIPC); TG, HDL-C, and ApoA1 (LIPG); TC, HDL-C, LDL-C, ApoA1 and ApoB (MTHFR); HDL-C and ApoA1 (MYLIP) in normal 


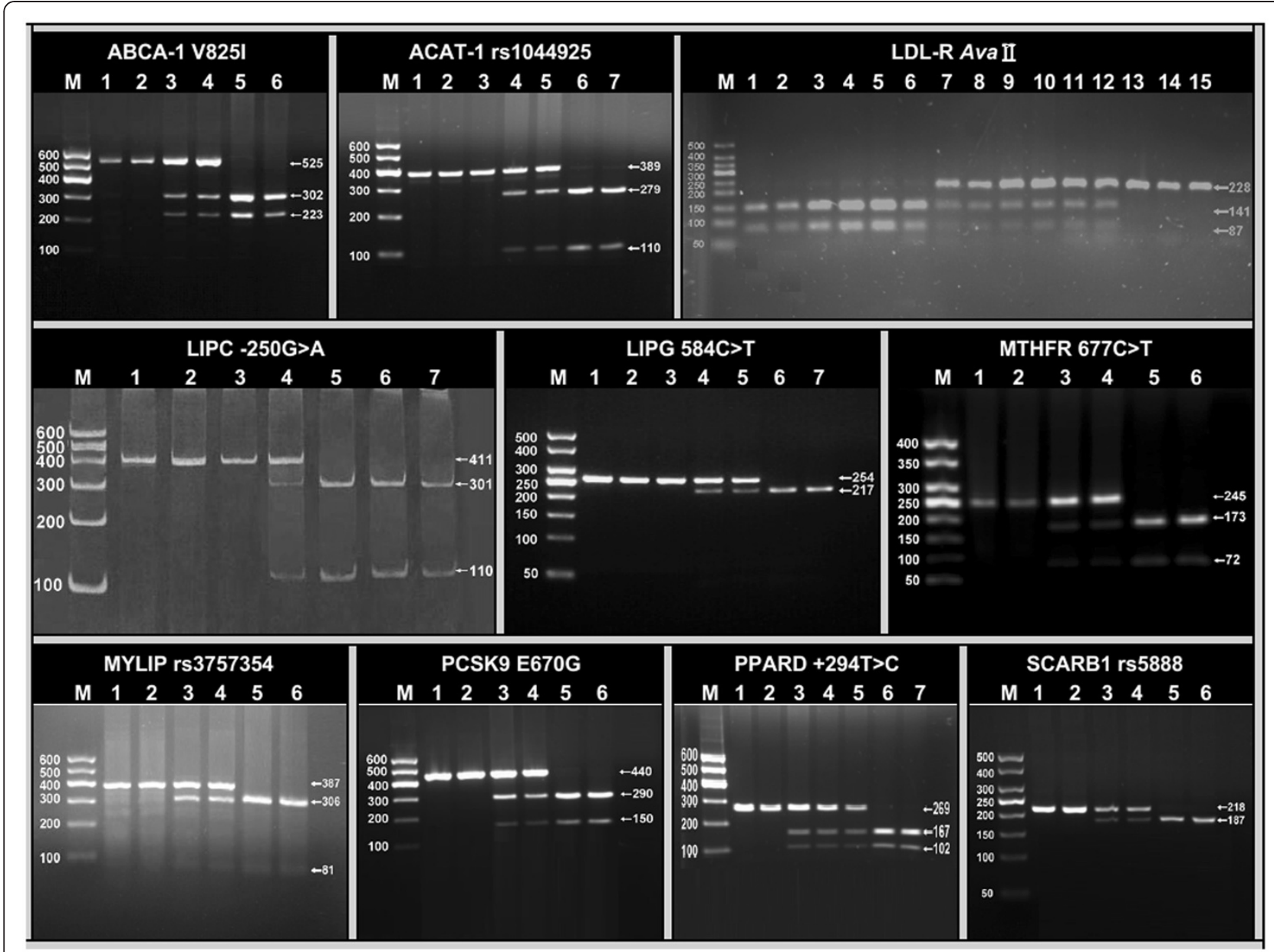

Figure 1 Genotyping of ten SNPs by polymerase chain reaction and restriction fragment length polymorphism. ABCA-1, ATP-binding cassette transporter A1; ACAT-1, acyl-CoA:cholesterol acyltransferase-1; LDL-R, low density lipoprotein receptor; LIPC, hepatic lipase gene; LIPG, endothelial lipase gene; MTHFR, methylenetetrahydrofolate reductase; MYLIP, the E3 ubiquitin ligase myosin regulatory light chain-interacting protein. PCSK9, proprotein convertase subtilisin-like kexin type 9; PPARD, peroxisome proliferator-activated receptor delta; SCARB1, Scavenger receptor class $B$ type 1 .

weight subjects were different among the genotypes $(P<0.01-0.001)$.

The levels of LDL-C, ApoB and ApoA1/ApoB (ABCA1); HDL-C, ApoA1, ApoB and ApoA1/ApoB (LIPC); TC, HDL-C, ApoA1 and ApoB (LIPG); TC, TG, HDL-C, LDL-C, ApoA1 and ApoB (MTHFR); TC, TG and ApoB (MYLIP); TG (PCSK9); TG and ApoA1 and ApoB (PPARD); and TC, HDL-C, LDL-C, ApoA1 and ApoB (SCARB1) in overweight/obese subjects were different among the genotypes $(P<0.01-0.001)$.

\section{Interactions of the SNPs and overweight/obesity on serum lipid levels}

The interactions of ten SNPs and overweight/obesity on serum lipid levels are given in Table 4. The SNPs of ABCA-1 (LDL-C and ApoA1/ApoB); LIPC (TC, LDL-C, ApoA1 and ApoB); LIPG (ApoB); MTHFR (TC, TG and
LDL-C); MYLIP (TC and TG); PCSK9 (TG, HDL-C, ApoB and ApoA1/ApoB); PPARD (TG and ApoA1/ ApoB); and SCARB1 (TG, ApoA1 and ApoB) were shown interactions with overweight/obesity to influence serum lipid levels $(P<0.05-0.001)$.

\section{Correlation between genotypes or alleles and serum lipid} parameters

The results of multiple linear regression analysis between genotypes or alleles and serum lipid parameters are shown in Tables 5, 6, 7. Serum lipid levels were also associated with the genotypes or alleles of several SNPs in the combined population of normal weight and overweight/obese subjects (Table 5), normal weight subjects (Table 6), and overweight/obese subjects (Table 7) ; respectively $(P<0.05-0.001)$. 


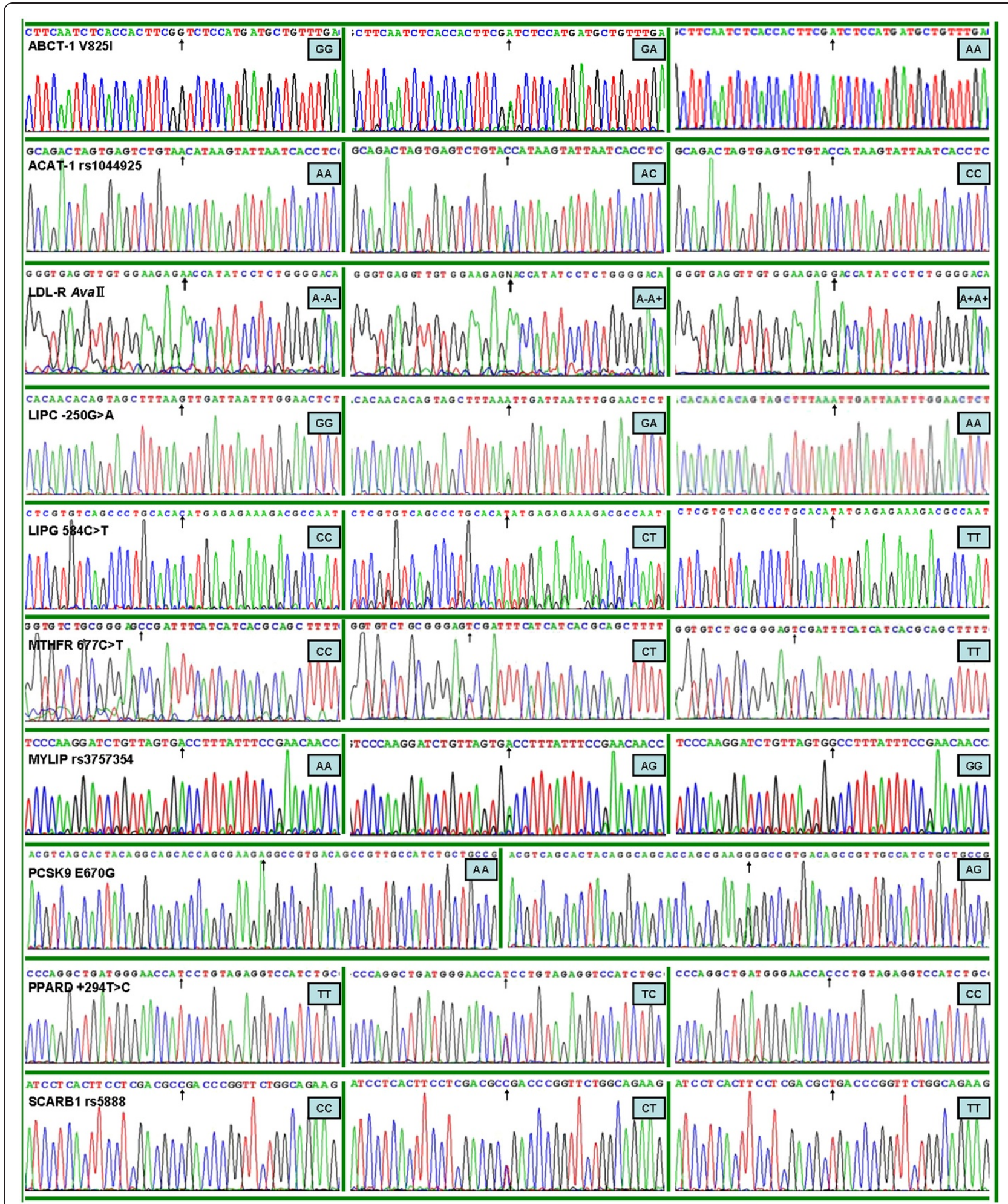

Figure 2 The parts of the nucleotide sequence of ten SNPs by direct sequencing. ABCA-1, ATP-binding cassette transporter A1; ACAT-1, acyl-CoA:cholesterol acyltransferase-1; LDL-R, low density lipoprotein receptor; LIPC, hepatic lipase gene; LIPG, endothelial lipase gene; MTHFR, methylenetetrahydrofolate reductase; MYLIP, the E3 ubiquitin ligase myosin regulatory light chain-interacting protein. PCSK9, proprotein convertase subtilisin-like kexin type 9; PPARD, peroxisome proliferator-activated receptor delta; SCARB1, Scavenger receptor class B type 1. 
Table 3 The genotypic and allelic frequencies between the subjects with normal weight and overweight/obesity [n (\%)]

\begin{tabular}{|c|c|c|c|c|c|}
\hline SNP & Genotype (Allele) & Normal weight $(n=978)$ & Overweight/obesity $(n=751)$ & $x^{2}$ & $P$ \\
\hline ABCA-1 V825I & GG & $326(33.3)$ & 269 (35.8) & & \\
\hline \multirow[t]{4}{*}{ (rs2066715) } & $\mathrm{GA}$ & $480(49.1)$ & $334(44.5)$ & & \\
\hline & AA & $172(17.6)$ & $148(19.7)$ & 3.708 & 0.157 \\
\hline & G & $1132(57.9)$ & $872(58.1)$ & & \\
\hline & A & $824(42.1)$ & $630(41.9)$ & 0.012 & 0.914 \\
\hline ACAT-1 & AA & $662(67.7)$ & $527(70.2)$ & & \\
\hline \multirow[t]{4}{*}{ (rs1044925) } & $A C$ & $279(28.5)$ & 205 (27.3) & & \\
\hline & CC & $37(3.8)$ & $19(2.5)$ & 2.671 & 0.263 \\
\hline & A & $1603(82.0)$ & 1259 (83.8) & & \\
\hline & C & $353(18.0)$ & $243(16.2)$ & 2.080 & 0.149 \\
\hline \multirow[t]{5}{*}{$\underline{\text { LDL-R Avall }}$} & A-A- & $527(53.9)$ & $389(51.8)$ & & \\
\hline & $\mathrm{A}-\mathrm{A}+$ & 371 (37.9) & 295 (39.3) & & \\
\hline & $\mathrm{A}+\mathrm{A}+$ & $80(8.2)$ & $67(8.9)$ & 0.824 & 0.662 \\
\hline & $A-$ & $1425(72.9)$ & $1073(71.4)$ & & \\
\hline & A+ & $531(27.1)$ & $429(28.6)$ & 0.848 & 0.357 \\
\hline LIPC $-250 G>A$ & GG & $480(49.1)$ & $233(31.0)$ & & \\
\hline \multirow[t]{4}{*}{ (rs2070895) } & GA & $425(43.5)$ & $432(57.5)$ & & \\
\hline & $\mathrm{AA}$ & $73(7.5)$ & 86 (11.5) & 57.882 & 0.000 \\
\hline & G & 1385 (70.8) & $898(59.8)$ & & \\
\hline & A & $571(29.2)$ & $604(40.2)$ & 45.999 & 0.000 \\
\hline LIPG 584C >T & CC & $454(46.4)$ & $308(41.0)$ & & \\
\hline \multirow[t]{4}{*}{ (rs2000813) } & $C T$ & $477(48.8)$ & $412(54.9)$ & & \\
\hline & $\pi$ & $47(4.8)$ & $31(4.1)$ & 6.314 & 0.043 \\
\hline & $C$ & $1385(70.8)$ & $1028(68.4)$ & & \\
\hline & $\mathrm{T}$ & $571(29.2)$ & $474(31.6)$ & 2.255 & 0.133 \\
\hline MTHFR $677 C>T$ & CC & $471(48.2)$ & $354(47.1)$ & & \\
\hline \multirow[t]{4}{*}{ (rs1801133) } & $C T$ & $441(45.1)$ & $341(45.4)$ & & \\
\hline & $\pi$ & $66(6.7)$ & $56(7.5)$ & 0.404 & 0.817 \\
\hline & C & $1383(70.7)$ & 1049 (69.8) & & \\
\hline & $T$ & $573(29.3)$ & $453(30.2)$ & 0.305 & 0.581 \\
\hline MYLIP & AA & $230(23.5)$ & $148(19.7)$ & & \\
\hline \multirow[t]{4}{*}{ (rs3757354) } & $A G$ & $477(48.8)$ & $363(48.3)$ & & \\
\hline & GG & $271(27.7)$ & $240(32.0)$ & 5.431 & 0.066 \\
\hline & A & $937(47.9)$ & $659(43.9)$ & & \\
\hline & G & 1019 (52.1) & $843(56.1)$ & 5.550 & 0.018 \\
\hline PCSK9 E670G & $\mathrm{AA}$ & $916(93.7)$ & $721(96.0)$ & & \\
\hline \multirow[t]{4}{*}{ (rs505151) } & $A G$ & $62(6.3)$ & $30(4.0)$ & & \\
\hline & GG & 0 & 0 & 4.636 & 0.031 \\
\hline & A & $1894(96.8)$ & $1472(98.0)$ & & \\
\hline & G & $62(3.2)$ & $30(2.0)$ & 4.509 & 0.034 \\
\hline PPARD +294 T $>C$ & $\pi$ & $559(57.2)$ & $396(52.7)$ & & \\
\hline \multirow[t]{3}{*}{ (rs2016520) } & TC & 354 (36.2) & $312(41.5)$ & & \\
\hline & CC & $65(6.6)$ & $43(5.7)$ & 5.239 & 0.073 \\
\hline & $\mathrm{T}$ & $1472(75.3)$ & $1104(73.5)$ & & \\
\hline
\end{tabular}


Table 3 The genotypic and allelic frequencies between the subjects with normal weight and overweight/obesity [n (\%)] (Continued)

\begin{tabular}{|c|c|c|c|c|c|}
\hline & $C$ & $484(24.7)$ & $398(26.5)$ & 1.375 & 0.241 \\
\hline SCARB1 & CC & $548(56.0)$ & $417(55.5)$ & & \\
\hline \multirow[t]{4}{*}{ (rs5888) } & $C T$ & $390(39.9)$ & $311(41.4)$ & & \\
\hline & $\pi$ & $40(4.1)$ & $23(3.1)$ & 1.497 & 0.473 \\
\hline & $C$ & $1486(76.0)$ & $1145(76.2)$ & & \\
\hline & $T$ & $470(24.0)$ & $357(23.8)$ & 0.032 & 0.859 \\
\hline
\end{tabular}

SNP, single nucleotide polymorphism; ABCA-1, ATP-binding cassette transporter A1; ACAT-1, acyl-CoA:cholesterol acyltransferase-1; LDL-R, low density lipoprotein receptor; LIPC, hepatic lipase gene; LIPG, endothelial lipase gene; MTHFR, methylenetetrahydrofolate reductase; MYLIP, the E3 ubiquitin ligase myosin regulatory light chain-interacting protein; PCSK9, proprotein convertase subtilisin-like kexin type 9; PPARD, peroxisome proliferator-activated receptor delta; SCARB1, Scavenger receptor class B type 1.

\section{Discussion}

\section{Serum lipid levels in the overweight/obese subjects}

In the present study, we showed that the levels of serum TC, TG, LDL-C, ApoA1, and ApoB were higher, and the levels of serum HDL-C and the ratio of ApoA1 to ApoB were lower in overweight/obese than in normal weight subjects. This is in agreement with those of previous studies [13-17]. Dyslipidemia in the obesity may be associated with insulin resistance [37-40]. Insulin is a lipidsynthetic hormone, thus alteration in a gene regulating insulin gene transcription may alter lipid metabolism as well and contribute to dyslipidemia. The liver is the main target organ of the insulin effect. Insulin resistance can descend the repression of insulin on the concentrations of plasma free fatty acids, increase the plasma levels of free fatty acids, promote free fatty acids into the liver, and stimulate the synthesis and release of very low density lipoprotein (VLDL) in the liver. At the same time, insulin resistances can also decline the activity of lipoprotein lipase (LPL), reduce the metabolism of VLDL, and increase the levels of plasma VLDL.

\section{Genotypic and allelic frequencies in different populations}

We showed that the genotypic and allelic frequencies of LIPC -250G>A and PCSK9 E670G were different between normal weight and overweight/obese subjects, the overweight/obese subjects had higher LIPC -250A and PCSK9 670A allele frequencies than normal weight subjects. The genotypic frequency of LIPG $584 \mathrm{C}>\mathrm{T}$ and allelic frequency of MYLIP rs3757354 were also different between normal weight and overweight/obese subjects. The allelic frequencies of LIPC -250G >A between African Americans and white Americans were quite different in several previous studies: the less common allele (-250A) of the LIPC polymorphisms in white Americans was the more common allele in African Americans $[41,42]$. The frequency of the LIPC -250A allele was found to range between 15-21\% among Caucasians [41], $32 \%$ among Brazilian [43], 39\% among TaiwaneseChinese [44], 45-53\% among African Americans [41,42] and $47 \%$ among Japanese-Americans [41]. The frequency of PCSK9 670G allele was rare in whites but present in approximately $24.8 \%$ of blacks [45]. Kotowski et al. [46] also reported that the minor-allele frequency (670G) in the Dallas Heart Study (DHS) was 3.6\% in whites, $4.2 \%$ in Hispanics, and $26.0 \%$ in blacks. The frequency of the PCSK9 670G allele in patients selected from Universitätsklinikum Hamburg-Eppendorf Martinistrasse, Hamburg, Germany was 5\% [47] which lies between that observed in the TexGen population, $4.4 \%$ and that reported for the Lipoprotein Coronary Atherosclerosis Study, $7.4 \%$ by Chen et al. [48] in their original study. There was no significant difference in the frequency of the PCSK9 670G allele in patients with LDL-C below the 50th percentile for age and sex, $4.4 \%$, those with LDL-C between the 50th and 95th percentiles, 6.4\% and those with LDL-C above the 95th percentile, 6.4\% [47]. The 670G carrier in Chinese Taiwanese was identified less frequently in patients with CAD than in controls (9.9\% vs. $11.9 \%)$, but the difference was not significant in a multivariable logistic regression analysis [49]. The frequency of LIPG $584 \mathrm{~T}$ allele was $10.3 \%$ in blacks, $31.2 \%$ in white controls, $32.6 \%$ in whites with high HDL-C [50], 26\% in the Lipoprotein and Coronary Atherosclerosis Study population (white individuals, but including 27 or 7\% African Americans) [51], 26\% in Japanese [52], and $21.6 \%$ in healthy school-aged Japanese children [53].

\section{Associations between SNPs and serum lipid levels}

The potential associations between these lipid-related gene SNPs and serum lipid levels [27-35] or obesity [54-65] in humans have been evaluated in a large number of studies. However, previous findings on the association of these SNPs with the changes in serum lipid levels or obesity (BMI) are inconsistent in different racial/ethnic groups. ABCA1 R219K (rs2230806) was associated with altered plasma HDL-C concentrations. This association on HDL-C levels was modified by BMI in a Chinese population from Chengdu area [54]. ABCA1 gene variant (R230C, 


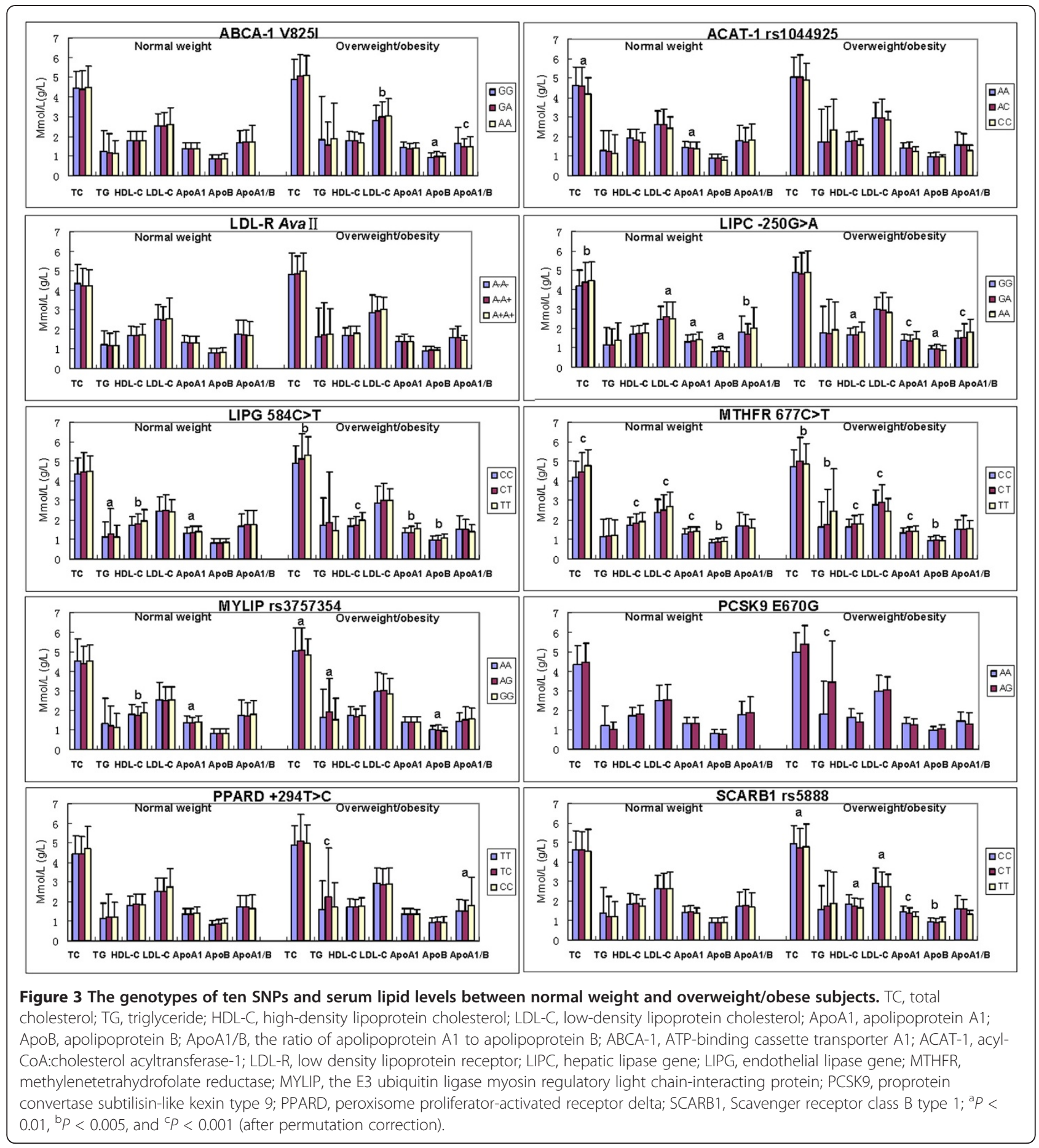

rs9282541) apparently exclusive to Native American individuals was also associated with low HDL-C levels, obesity and type 2 diabetes in Mexican Mestizos. The 230C allele was associated with lower HDL-C levels and with higher BMI in the combined analysis of Native American populations [55]. Kitjaroentham et al. [56] showed that overweight/obese men carrying the mutant allele of ABCA1
R219K had lower HDL-C levels than the controls. However, no positive association was observed using bivariate logistic regression analysis. On the contrary, there was no difference in HDL-C levels among genotypes in ABCA1 I883M (rs4149313) polymorphism. No difference was detected in genotypic frequency between the overweight/ obese and control subjects for both polymorphisms. Two 
Table 4 Interactions of several SNPs and overweight/obesity on serum lipid levels

\begin{tabular}{|c|c|c|c|c|c|c|c|c|}
\hline SNP & Genotype & $\mathrm{TC}(\mathrm{mmol} / \mathrm{L})$ & TG (mmol/L) & HDL-C (mmol/L) & LDL-C (mmol/L) & ApoA1 (g/L) & ApoB (g/L) & ApoA1/ ApoB \\
\hline ABCA-1 V825I & GG & - & - & - & - & - & - & - \\
\hline \multirow[t]{4}{*}{ (rs2066715) } & GA & - & - & - & $\uparrow$ & - & - & $\downarrow$ \\
\hline & AA & - & - & - & $\uparrow$ & - & - & $\downarrow$ \\
\hline & $F$ & 1.473 & 2.937 & 1.717 & 3.687 & 1.913 & 2.941 & 6.485 \\
\hline & $P$ & 0.230 & 0.053 & 0.180 & $0.005^{c}$ & 0.148 & 0.053 & $0.000^{c}$ \\
\hline ACAT-1 rs1044925 & $\mathrm{AA}$ & - & - & - & - & - & - & - \\
\hline \multirow[t]{4}{*}{ (rs1044925) } & $A C$ & - & - & - & - & - & - & - \\
\hline & $\mathrm{CC}$ & - & - & - & - & - & - & - \\
\hline & $F$ & 0.475 & 1.457 & 0.341 & 0.320 & 1.635 & 1.071 & 1.944 \\
\hline & $P$ & 0.622 & 0.233 & 0.711 & 0.726 & 0.195 & 0.343 & 0.143 \\
\hline \multirow[t]{5}{*}{$\underline{\text { LDL-R Avall }}$} & $A-A-$ & - & - & - & - & - & - & - \\
\hline & $\mathrm{A}-\mathrm{A}+$ & - & - & - & - & - & - & - \\
\hline & $\mathrm{A}+\mathrm{A}+$ & - & - & - & - & - & - & - \\
\hline & $F$ & 1.681 & 0.242 & 0.553 & 0.857 & 1.377 & 0.430 & 0.462 \\
\hline & $P$ & 0.186 & 0.785 & 0.576 & 0.425 & 0.253 & 0.650 & 0.630 \\
\hline LIPC $-250 G>A$ & GG & $\uparrow$ & - & - & $\uparrow$ & - & $\uparrow$ & - \\
\hline \multirow[t]{4}{*}{ (rs2070895) } & GA & - & - & - & - & - & $\uparrow$ & - \\
\hline & $\mathrm{AA}$ & - & - & - & - & $\uparrow$ & - & - \\
\hline & $F$ & 3.733 & 0.266 & 1.584 & 3.345 & 3.292 & 4.138 & 2.116 \\
\hline & $P$ & $0.005^{c}$ & 0.766 & 0.205 & $0.007^{c}$ & $0.007^{c}$ & $0.003^{c}$ & 0.121 \\
\hline LIPG 584C>T & $\mathrm{CC}$ & - & - & - & - & - & - & - \\
\hline \multirow[t]{4}{*}{ (rs2000813) } & $\mathrm{CT}$ & - & - & - & - & - & - & - \\
\hline & $\pi$ & - & - & - & - & - & $\uparrow$ & - \\
\hline & $F$ & 1.286 & 0.210 & 0.357 & 1.452 & 2.195 & 3.616 & 1.812 \\
\hline & $P$ & 0.277 & 0.810 & 0.700 & 0.234 & 0.112 & $0.005^{c}$ & 0.164 \\
\hline MTHFR $677 C>T$ & $\mathrm{CC}$ & - & - & - & $\uparrow$ & - & - & - \\
\hline \multirow[t]{4}{*}{ (rs1801133) } & $\mathrm{CT}$ & $\uparrow$ & - & - & - & - & - & - \\
\hline & $\pi$ & - & $\uparrow$ & - & $\downarrow$ & - & - & - \\
\hline & $F$ & 3.110 & 3.463 & 0.627 & 9.236 & 0.058 & 2.684 & 0.675 \\
\hline & $P$ & $0.009^{c}$ & $0.006^{c}$ & 0.534 & $0.000^{c}$ & 0.944 & 0.069 & 0.509 \\
\hline MYLIP & AA & - & - & - & - & - & - & - \\
\hline \multirow[t]{4}{*}{ (rs3757354) } & $A G$ & $\uparrow$ & $\uparrow$ & - & - & - & - & - \\
\hline & GG & - & - & - & - & - & - & - \\
\hline & $F$ & 6.864 & 4.325 & 1.818 & 2.495 & 0.684 & 1.895 & 1.388 \\
\hline & $P$ & $0.000^{c}$ & $0.003^{c}$ & 0.307 & 0.083 & 0.505 & 0.151 & 0.250 \\
\hline PCSK9 E670G & $\mathrm{AA}$ & - & - & - & - & - & - & - \\
\hline \multirow[t]{3}{*}{ (rs505151) } & $A G$ & - & $\uparrow$ & $\downarrow$ & - & - & $\uparrow$ & $\downarrow$ \\
\hline & $F$ & 0.980 & 25.662 & 7.831 & 0.002 & 1.371 & 6.319 & 4.357 \\
\hline & $P$ & 0.322 & $0.000^{c}$ & $0.001^{c}$ & 0.968 & 0.242 & $0.002^{c}$ & $0.007^{c}$ \\
\hline PPARD $+294 T>C$ & $\pi$ & - & - & - & - & - & - & - \\
\hline \multirow[t]{4}{*}{ (rs2016520) } & $\mathrm{TC}$ & - & $\uparrow$ & - & - & - & - & - \\
\hline & $\mathrm{CC}$ & - & - & - & - & - & - & $\uparrow$ \\
\hline & $F$ & 1.832 & 5.737 & 1.235 & 1.087 & 0.171 & 1.362 & 3.985 \\
\hline & $P$ & 0.160 & $0.001^{c}$ & 0.291 & 0.337 & 0.843 & 0.257 & $0.004^{c}$ \\
\hline
\end{tabular}


Table 4 Interactions of several SNPs and overweight/obesity on serum lipid levels (Continued)

\begin{tabular}{lllllllll}
\hline SCARB1 & CC & - & - & - & - & - & $\uparrow$ & - \\
\hline (rs5888) & CT & - & - & - & - & $\downarrow$ & - \\
\hline & $T$ & - & $\uparrow$ & - & - & $\downarrow$ & - \\
\hline & $F$ & 1.809 & 4.396 & 1.720 & 2.211 & 3.226 & 3.118 & 0.051 \\
\hline & $P$ & 0.164 & $0.002^{C}$ & 0.179 & 0.110 & $0.008^{C}$ & $0.009^{\complement}$ & 0.778 \\
\hline
\end{tabular}

SNP, single nucleotide polymorphism; TC, total cholesterol; TG, triglyceride; HDL-C, high-density lipoprotein cholesterol; LDL-C, low-density lipoprotein cholesterol; ApoA1, apolipoprotein A1; ApoB, apolipoprotein B; ApoA1/ApoB, the ratio of apolipoprotein A1 to apolipoprotein B; ABCA-1, ATP-binding cassette transporter A1; ACAT-1, acyl-CoA:cholesterol acyltransferase-1; LDL-R, low density lipoprotein receptor; LIPC, hepatic lipase gene; LIPG, endothelial lipase gene; MTHFR, methylenetetrahydrofolate reductase; MYLIP, the E3 ubiquitin ligase myosin regulatory light chain-interacting protein; PCSK9, proprotein convertase subtilisin-like kexin type 9; PPARD, peroxisome proliferator-activated receptor delta; SCARB1, Scavenger receptor class B type 1 ; " $\mathrm{C}^{\text {" }}$ is the $P$-value after permutation correction. $\uparrow:$ genotype and overweight/obesity interactions to increase serum lipid levels; $\downarrow$ : genotype and overweight/obesity interactions to decrease serum lipid levels; -: no interaction of genotypes and overweight/obesity on serum lipid levels.

previous cross-sectional association studies showed that LDL-R ApaLI and HincII polymorphisms were associated with obesity in essential hypertensives but not in normotensives [57,58]. Griffiths et al. [59] showed that LDL-R microsatellite marker, located more towards the $3 /$ end of the gene, was associated with obesity in the normotensive population studied. There was also a significant association between variants of the LDL-R microsatellite and obesity, in the overall tested population, due to a contributing effect in females, but not in males [60]. These results indicate that LDL-R could play an important role in the development of obesity, which might be independent of hypertension or sex. MTHFR 677T allele was associated with obesity, hypertriglyceridemia and low HDL-C levels [61]. Birth weights were lower in 677TT than in 677CC and $677 \mathrm{CT}$ subjects, as well as birth lengths [62]. In subjects with and without type 2 diabetes, PPARD $+294 \mathrm{~T}>\mathrm{C}$ was associated with BMI, HDL-C, leptin, and TNF-alpha and was dependent on gender [63]. BMI in metabolic syndrome patients with $+294 \mathrm{C}$ allele carriers were significantly higher than that of TT genotype [64]. However, Aberle et al. [65] showed that the PPARD $+294 \mathrm{C}$ allele was significantly associated with a lower BMI. In this study, we showed that the levels of TC, ApoA1 (ABCA-1); TC, LDL-C, ApoA1, ApoB and ApoA1/ApoB (LIPC); TG, HDL-C, and ApoA1 (LIPG); TC, HDL-C, LDL-C, ApoA1 and ApoB (MTHFR); HDL-C and ApoA1 (MYLIP) in normal weight subjects were different among the genotypes. The levels of LDL-C, ApoB and ApoA1/ApoB (ABCA-1); HDL-C, ApoA1, ApoB and ApoA1/ApoB (LIPC); TC, HDL-C, ApoA1 and ApoB (LIPG); TC, TG, HDL-C, LDLC, ApoA1 and ApoB (MTHFR); TC, TG and ApoB (MYLIP); TG (PCSK9); TG and ApoA1 and ApoB (PPARD); and TC, HDL-C, LDL-C, ApoA1 and ApoB (SCARB1) in overweight/obese subjects were also different among the genotypes. Serum lipid levels were also associated with the genotypes or alleles of several SNPs in the combined population of normal weight and overweight/obese subjects, normal weight subjects, and overweight/obese subjects; respectively. These results suggest that the associations of these SNPs and serum lipid levels are different between normal weight and overweight/ obese subjects.

\section{Interactions between SNPs and overweight/obesity on serum lipid levels}

The interactions of SNPs and overweight/obesity on serum lipid parameters are limited. In an examination of the effect of body fat on the genotypic effects in the children, Talmud et al. [66] showed that there was significant interaction between tertiles of sum of skinfold thickness and the LIPC $-480 \mathrm{C}>\mathrm{T}$ genotype in determining HDL-C levels. In the lowest tertile, carriers of the $-480 \mathrm{~T}$ allele had lower mean HDL-C levels, whereas in the two upper tertiles, $-480 \mathrm{~T}$ carriers had higher mean HDL-C levels when compared with the $\mathrm{CC}$ homozygotes. In a previous study [67], the interaction between BMI, the LIPC $-514 \mathrm{C}>\mathrm{T}$ polymorphism, and hepatic lipase activity was examined in white and African American men. The results showed that increased BMI was associated with increased hepatic lipase activity in men. A striking additive effect of BMI and the LIPC $-514 \mathrm{C}>\mathrm{T}$ polymorphism on hepatic lipase activity was observed. The joint effects of BMI and LIPC $-514 \mathrm{C}>\mathrm{T}$ genotypes strongly influenced hepatic lipase activity and were significantly greater than the effects of either factor considered alone. LIPC $-514 \mathrm{C}>\mathrm{T}$ and LIPC -250G >A SNPs have been demonstrated in complete linkage disequilibrium [30]. There was evidence for an interaction of the LIPC promoter polymorphism with visceral obesity in determining the level of hepatic lipase activity, the presence of the LIPC $-514 \mathrm{~T}$ allele seems to attenuate the increase in hepatic lipase activity with high levels of intra-abdominal fat [68]. The interactions of LIPC $-514 \mathrm{C}>\mathrm{T}$ and LIPC -250G > A SNPs and obesity on HDL-C levels were also observed in Taiwanese-Chinese men but not in women [44]. For males, significant interactions were noted between the two studied polymorphisms and obesity on HDL-C levels. For obese males, significantly higher HDL-C levels were found for carriers of the $-514 \mathrm{~T}$ and -250A alleles in comparison with non-carriers. In contrast, no significant differences were found for nonobese male subjects bearing different genotypes of the 
Table 5 Correlation between genotypes or alleles and serum lipid levels in the total population

\begin{tabular}{|c|c|c|c|c|c|c|}
\hline Lipid & Genotype/allele & Unstandardized coefficient & Std. error & Standardized coefficient & $t$ & $P$ \\
\hline \multirow[t]{7}{*}{$\mathrm{TC}$} & ACAT-1 rs1044925 genotype & -0.099 & 0.043 & -0.053 & -2.287 & 0.022 \\
\hline & LIPC -250G $>$ A allele & 0.101 & 0.046 & 0.050 & 2.170 & 0.030 \\
\hline & LIPG 584C>T genotype & 0.149 & 0.043 & 0.079 & 3.503 & 0.000 \\
\hline & LIPG 584C >T allele & 0.169 & 0.049 & 0.077 & 3.425 & 0.001 \\
\hline & MTHFR 677C>T genotype & 0.218 & 0.037 & 0.133 & 5.854 & 0.000 \\
\hline & MTHFR $677 C>$ T allele & 0.269 & 0.046 & 0.133 & 5.841 & 0.000 \\
\hline & PPARD +294 T $>$ C allele & 0.147 & 0.050 & 0.068 & 2.963 & 0.003 \\
\hline \multirow[t]{4}{*}{$\underline{T G}$} & MTHFR $677 C>$ T genotype & 0.146 & 0.054 & 0.062 & 2.701 & 0.007 \\
\hline & MYLIP rs3757354 genotype & -0.102 & 0.042 & -0.057 & -2.456 & 0.014 \\
\hline & PPARD +294 T $>$ C allele & 0.321 & 0.086 & 0.087 & 3.732 & 0.000 \\
\hline & SCARB1 rs5888 genotype & -0.041 & 0.023 & -0.049 & -2.039 & 0.042 \\
\hline \multirow[t]{8}{*}{$\mathrm{HDL}-\mathrm{C}$} & ACAT-1 rs1044925 genotype & -0.057 & 0.022 & -0.062 & -2.643 & 0.008 \\
\hline & ACAT-1 rs1044925 allele & -0.051 & 0.025 & -0.048 & -2.024 & 0.043 \\
\hline & LIPC -250G>A genotype & 0.038 & 0.016 & 0.055 & 2.366 & 0.018 \\
\hline & LIPG 584C>T genotype & 0.086 & 0.018 & 0.108 & 4.667 & 0.000 \\
\hline & LIPG 584C>T allele & 0.080 & 0.021 & 0.087 & 3.762 & 0.000 \\
\hline & MTHFR 677C>T genotype & 0.097 & 0.017 & 0.132 & 5.718 & 0.000 \\
\hline & MTHFR $677 C>$ T allele & 0.123 & 0.021 & 0.136 & 5.868 & 0.000 \\
\hline & MYLIP rs3757354 genotype & 0.036 & 0.015 & 0.058 & 2.465 & 0.014 \\
\hline \multirow[t]{3}{*}{$\mathrm{LDL}-\mathrm{C}$} & ABCA-1 V825I genotype & 0.075 & 0.025 & 0.068 & 2.954 & 0.003 \\
\hline & MTHFR 677C>T genotype & 0.075 & 0.029 & 0.059 & 2.562 & 0.010 \\
\hline & MTHFR $677 \mathrm{C}>$ T allele & 0.120 & 0.036 & 0.077 & 3.334 & 0.001 \\
\hline \multirow[t]{7}{*}{ ApoA1 } & ACAT-1 rs1044925 genotype & -0.042 & 0.013 & -0.074 & -3.143 & 0.002 \\
\hline & ACAT-1 rs1044925 allele & -0.042 & 0.016 & -0.063 & -2.672 & 0.008 \\
\hline & LIPC -250G>A genotype & 0.036 & 0.012 & 0.068 & 3.020 & 0.003 \\
\hline & LIPG 584C>T genotype & 0.040 & 0.012 & 0.076 & 3.303 & 0.001 \\
\hline & LIPG 584C >T allele & 0.039 & 0.014 & 0.064 & 2.781 & 0.005 \\
\hline & MTHFR 677C>T genotype & 0.053 & 0.010 & 0.118 & 5.130 & 0.000 \\
\hline & MTHFR $677 C>$ T allele & 0.068 & 0.013 & 0.123 & 5.338 & 0.000 \\
\hline \multirow[t]{2}{*}{ ApoB } & MTHFR 677C>T genotype & 0.032 & 0.008 & 0.086 & 3.781 & 0.000 \\
\hline & MTHFR $677 \mathrm{C}>$ T allele & 0.042 & 0.010 & 0.092 & 4.049 & 0.000 \\
\hline ApoA1/ApoB & LIPC -250G>A genotype & 0.070 & 0.026 & 0.063 & 2.649 & 0.008 \\
\hline
\end{tabular}

TC, total cholesterol; TG, triglyceride; HDL-C, high-density lipoprotein cholesterol; LDL-C, low-density lipoprotein cholesterol; ApoA1, apolipoprotein A1; ApoB, apolipoprotein $B ; A$ ApoA1/ApoB, the ratio of apolipoprotein A1 to apolipoprotein B; ABCA-1, ATP-binding cassette transporter A1; ACAT-1, acyl-CoA:cholesterol acyltransferase-1; LDL-R, low density lipoprotein receptor; LIPC, hepatic lipase gene; LIPG, endothelial lipase gene; MTHFR, methylenetetrahydrofolate reductase; MYLIP, the E3 ubiquitin ligase myosin regulatory light chain-interacting protein; PCSK9, proprotein convertase subtilisin-like kexin type 9; PPARD, peroxisome proliferator-activated receptor delta; SCARB1, Scavenger receptor class B type 1.

LIPC $-514 \mathrm{C}>\mathrm{T}$ and $-250 \mathrm{G}>\mathrm{A}$ polymorphisms. For both obese women and non-obese ones, no significant difference was detected between different genotypes of the two studied polymorphisms and HDL-C levels [44]. The beneficial effect of the LIPC $-514 \mathrm{~T}$ allele on plasma $\mathrm{HDL}_{2}-\mathrm{C}$ levels was abolished in the presence of visceral obesity [69]. Swarbrick et al. [70] reported that obese subjects carrying the Ala allele of the Pro12Ala polymorphism of the PPAR-gamma2 gene, but not the non-obese analogs, had a greater risk of developing combined hyperlipidemia and low-HDL-C levels. In the current study, we provide important insights for the interactions of several SNPs and overweight/obesity on serum lipid phenotypes. The SNPs of ABCA-1 (LDL-C and ApoA1/ApoB); LIPC (TC, LDLC, ApoA1 and ApoB); LIPG (ApoB); MTHFR (TC, TG and LDL-C); MYLIP (TC and TG); PCSK9 (TG, HDL-C, ApoB and ApoA1/ApoB); PPARD (TG and ApoA1/ ApoB); and SCARB1 (TG, ApoA1 and ApoB) interacted with overweight/obesity to modulate serum lipid levels. These findings suggest that some serum lipid parameters in our study subjects were partly influenced by the interactions of several SNPs and overweight/obesity. To the best of our knowledge, the interactions of ABCA-1, LIPG, MTHFR, MYLIP, PCSK9, PPARD, and SCARB1 SNPs and 
Table 6 Correlation between genotypes or alleles and serum lipid levels in the normal weight subjects

\begin{tabular}{|c|c|c|c|c|c|c|}
\hline Lipid & Genotype/allele & Unstandardized coefficient & Std. error & Standardized coefficient & $t$ & $P$ \\
\hline \multirow[t]{8}{*}{$\mathrm{TC}$} & ACAT-1 rs1044925 genotype & -0.131 & 0.053 & -0.078 & -2.477 & 0.013 \\
\hline & LDL-R Avall genotype & -0.089 & 0.043 & -0.062 & -2.049 & 0.041 \\
\hline & LDL-R Avall allele & -0.121 & 0.056 & -0.066 & -2.178 & 0.030 \\
\hline & LIPC -250G>A genotype & 0.156 & 0.045 & 0.106 & 3.443 & 0.001 \\
\hline & LIPC -250G >A allele & 0.204 & 0.057 & 0.111 & 3.593 & 0.000 \\
\hline & MTHFR 677 C $>$ T genotype & 0.266 & 0.046 & 0.179 & 5.768 & 0.000 \\
\hline & MTHFR 677C>T allele & 0.290 & 0.057 & 0.158 & 5.089 & 0.000 \\
\hline & PPARD +294T>C genotype & 0.101 & 0.048 & 0.066 & 2.104 & 0.036 \\
\hline \multirow[t]{3}{*}{ TG } & LIPC -250G $>$ A allele & 0.149 & 0.065 & 0.072 & 2.292 & 0.022 \\
\hline & MYLIP rs3757354 genotype & -0.101 & 0.045 & -0.071 & -2.251 & 0.025 \\
\hline & SCARB1 rs5888 genotype & -0.142 & 0.066 & -0.068 & -2.157 & 0.031 \\
\hline \multirow[t]{7}{*}{$\mathrm{HDL}-\mathrm{C}$} & ACAT-1 rs1044925 genotype & -0.061 & 0.028 & -0.068 & -2.177 & 0.030 \\
\hline & LIPC -250G>A genotype & 0.045 & 0.022 & 0.062 & 2.040 & 0.042 \\
\hline & LIPG 584C>T genotype & 0.085 & 0.025 & 0.104 & 3.364 & 0.001 \\
\hline & LIPG 584C>T allele & 0.085 & 0.030 & 0.089 & 2.877 & 0.004 \\
\hline & MTHFR 677C>T genotype & 0.105 & 0.024 & 0.134 & 4.361 & 0.000 \\
\hline & MTHFR 677C>T allele & 0.129 & 0.030 & 0.134 & 4.352 & 0.000 \\
\hline & MYLIP rs3757354 genotype & 0.054 & 0.021 & 0.082 & 2.609 & 0.009 \\
\hline \multirow[t]{4}{*}{$\underline{L D L-C}$} & LIPC -250G>A genotype & 0.080 & 0.037 & 0.067 & 2.171 & 0.030 \\
\hline & LIPC -250G >A allele & 0.125 & 0.046 & 0.084 & 2.713 & 0.007 \\
\hline & MTHFR $677 C>$ T genotype & 0.146 & 0.036 & 0.126 & 4.016 & 0.000 \\
\hline & MTHFR 677C>T allele & 0.156 & 0.045 & 0.109 & 3.493 & 0.000 \\
\hline \multirow[t]{8}{*}{ ApoA1 } & ACAT-1 rs1044925 genotype & -0.047 & 0.018 & -0.080 & -2.606 & 0.009 \\
\hline & LIPC -250G>A genotype & 0.048 & 0.016 & 0.087 & 2.969 & 0.003 \\
\hline & LIPC -250G >A allele & 0.051 & 0.020 & 0.074 & 2.516 & 0.012 \\
\hline & LIPG 584C>T genotype & 0.040 & 0.016 & 0.075 & 2.467 & 0.014 \\
\hline & LIPG 584C>T allele & 0.049 & 0.019 & 0.079 & 2.608 & 0.009 \\
\hline & MTHFR 677C>T genotype & 0.057 & 0.014 & 0.121 & 3.965 & 0.000 \\
\hline & MTHFR 677C>T allele & 0.071 & 0.018 & 0.122 & 4.019 & 0.000 \\
\hline & SCARB1 rs5888 genotype & -0.034 & 0.012 & -0.065 & -2.742 & 0.006 \\
\hline \multirow[t]{4}{*}{ ApoB } & LIPC -250G >A allele & 0.033 & 0.013 & 0.078 & 2.498 & 0.013 \\
\hline & MTHFR 677C>T genotype & 0.037 & 0.011 & 0.105 & 3.359 & 0.001 \\
\hline & MTHFR 677C > T allele & 0.039 & 0.013 & 0.091 & 2.904 & 0.004 \\
\hline & SCARB1 rs5888 allele & -0.012 & 0.010 & -0.048 & -2.043 & 0.041 \\
\hline
\end{tabular}

TC, total cholesterol; TG, triglyceride; HDL-C, high-density lipoprotein cholesterol; LDL-C, low-density lipoprotein cholesterol; ApoA1, apolipoprotein A1; ApoB, apolipoprotein $B ; A$ ApoA1/ApoB, the ratio of apolipoprotein A1 to apolipoprotein B; ABCA-1, ATP-binding cassette transporter A1; ACAT-1, acyl-CoA:cholesterol acyltransferase-1; LDL-R, low density lipoprotein receptor; LIPC, hepatic lipase gene; LIPG, endothelial lipase gene; MTHFR, methylenetetrahydrofolate reductase; MYLIP, the E3 ubiquitin ligase myosin regulatory light chain-interacting protein; PCSK9, proprotein convertase subtilisin-like kexin type 9; PPARD, peroxisome proliferator-activated receptor delta; SCARB1, Scavenger receptor class B type 1.

overweight/obesity on serum lipid parameters have not been previously explored.

\section{Study limitations}

This study has several limitations. First, the levels of education, weight, systolic blood pressure, diastolic blood pressure, and the percentages of subjects who consumed alcohol were higher in overweight/obese than in normal weight subjects, whereas the percentages of subjects who smoked cigarettes were lower in overweight/obese than in normal weight subjects. Although sex, age, education level, physical activity, blood pressure, alcohol consumption, and cigarette smoking have been adjusted for the statistical analysis, we could not completely eliminate the potential effects of these factors on serum lipid levels among different genotypes in both groups. Second, the diet was not adjusted for the statistical analysis. In the present study, however, the diet in this isolated population is consistent throughout the year and among individuals because of 
Table 7 Correlation between genotypes or alleles and serum lipid levels in the overweight/obese subjects

\begin{tabular}{|c|c|c|c|c|c|c|}
\hline Lipid & Genotype/allele & Unstandardized coefficient & Std. cp error & Standardized coefficient & $t$ & $P$ \\
\hline \multirow[t]{8}{*}{$\mathrm{TC}$} & ABCA-1 V825I all'ele & 0.162 & 0.078 & 0.074 & 2.078 & 0.038 \\
\hline & LIPG 584C>T genotype & 0.228 & 0.073 & 0.109 & 3.122 & 0.002 \\
\hline & LIPG 584C>T allele & 0.251 & 0.084 & 0.105 & 2.993 & 0.003 \\
\hline & MTHFR 677C>T genotype & 0.158 & 0.060 & 0.092 & 2.624 & 0.009 \\
\hline & MTHFR 677C $>$ T allele & 0.245 & 0.075 & 0.115 & 3.267 & 0.001 \\
\hline & MYLIP rs3757354 genotype & -0.121 & 0.054 & -0.082 & -2.264 & 0.024 \\
\hline & PPARD +294 T $>$ C allele & 0.222 & 0.083 & 0.096 & 2.666 & 0.008 \\
\hline & SCARB1 rs5888 allele & -0.182 & 0.069 & -0.095 & -2.633 & 0.009 \\
\hline \multirow[t]{4}{*}{ TG } & MTHFR 677C>T genotype & 0.272 & 0.106 & 0.090 & 2.556 & 0.011 \\
\hline & PCSK9 E670G genotype & 1.251 & 0.309 & 0.137 & 4.053 & 0.000 \\
\hline & PPARD +294T>C allele & 0.675 & 0.179 & 0.133 & 3.763 & 0.000 \\
\hline & SCARB1 rs5888 genotype & 0.232 & 0.099 & 0.084 & 2.337 & 0.020 \\
\hline \multirow[t]{7}{*}{$\mathrm{HDL}-\mathrm{C}$} & ABCA-1 V825I genotype & -0.048 & 0.022 & -0.077 & -2.193 & 0.029 \\
\hline & LIPG 584C>T genotype & 0.087 & 0.026 & 0.114 & 3.337 & 0.001 \\
\hline & LIPG 584C>T allele & 0.068 & 0.030 & 0.078 & 2.270 & 0.024 \\
\hline & MTHFR 677C>T genotype & 0.097 & 0.023 & 0.146 & 4.122 & 0.000 \\
\hline & MTHFR $677 C>$ T allele & 0.138 & 0.029 & 0.167 & 4.721 & 0.000 \\
\hline & PCSK9 E670G genotype & -0.167 & 0.075 & -0.076 & -2.234 & 0.026 \\
\hline & SCARB1 rs5888 genotype & -0.069 & 0.029 & -0.084 & -2.265 & 0.018 \\
\hline \multirow[t]{4}{*}{ LDL-C } & ABCA-1 V825I genotype & 0.134 & 0.040 & 0.119 & 3.308 & 0.001 \\
\hline & ABCA-1 V825I allele & 0.228 & 0.061 & 0.134 & 3.726 & 0.000 \\
\hline & LIPG 584C>T genotype & 0.115 & 0.054 & 0.076 & 2.106 & 0.035 \\
\hline & LIPG 584C>T allele & 0.131 & 0.062 & 0.077 & 2.116 & 0.035 \\
\hline \multirow[t]{5}{*}{ ApoA1 } & ABCA-1 V825I allele & -0.044 & 0.020 & -0.075 & -2.138 & 0.033 \\
\hline & LIPG 584C>T genotype & 0.036 & 0.018 & 0.071 & 2.038 & 0.042 \\
\hline & MTHFR 677C>T genotype & 0.057 & 0.015 & 0.137 & 3.862 & 0.000 \\
\hline & MTHFR $677 C>$ T allele & 0.076 & 0.018 & 0.145 & 4.099 & 0.000 \\
\hline & SCARB1 rs5888 genotype & -0.062 & 0.018 & -0.122 & -3.523 & 0.000 \\
\hline \multirow[t]{7}{*}{ ApoB } & ABCA-1 V825I genotype & 0.023 & 0.011 & 0.074 & 2.041 & 0.042 \\
\hline & ABCA-1 V825I allele & 0.046 & 0.017 & 0.096 & 2.652 & 0.008 \\
\hline & LIPC -250G>A genotype & -0.034 & 0.012 & -0.101 & -2.777 & 0.006 \\
\hline & MTHFR $677 C>T$ genotype & 0.028 & 0.013 & 0.077 & 2.147 & 0.032 \\
\hline & MTHFR $677 C>$ T allele & 0.048 & 0.016 & 0.107 & 2.992 & 0.003 \\
\hline & MYLIP rs3757354 genotype & -0.026 & 0.012 & -0.079 & -2.190 & 0.029 \\
\hline & SCARB1 rs5888 allele & -0.052 & 0.015 & -0.129 & -3.587 & 0.000 \\
\hline \multirow[t]{5}{*}{ ApoA1/ApoB } & ABCA-1 V825I genotype & -0.093 & 0.029 & -0.114 & -3.168 & 0.002 \\
\hline & ABCA-1 V825I allele & -0.185 & 0.044 & -0.149 & -4.172 & 0.000 \\
\hline & LIPC -250G>A genotype & 0.132 & 0.036 & 0.132 & 3.698 & 0.000 \\
\hline & LIPC -250G>A allele & 0.114 & 0.048 & 0.085 & 2.361 & 0.018 \\
\hline & MYLIP rs3757354 genotype & 0.058 & 0.030 & 0.071 & 1.965 & 0.050 \\
\hline
\end{tabular}

TC, total cholesterol; TG, triglyceride; HDL-C, high-density lipoprotein cholesterol; LDL-C, low-density lipoprotein cholesterol; ApoA1, apolipoprotein A1; ApoB, apolipoprotein $B ; A p o A 1 / A p o B$, the ratio of apolipoprotein $A 1$ to apolipoprotein $B ; A B C A-1$, ATP-binding cassette transporter A1; ACAT-1, acyl-CoA:cholesterol acyltransferase-1; LDL-R, low density lipoprotein receptor; LIPC, hepatic lipase gene; LIPG, endothelial lipase gene; MTHFR, methylenetetrahydrofolate reductase; MYLIP, the E3 ubiquitin ligase myosin regulatory light chain-interacting protein; PCSK9, proprotein convertase subtilisin-like kexin type 9; PPARD, peroxisome proliferator-activated receptor delta; SCARB1, Scavenger receptor class B type 1. 
the Bai Ku Yao's reliance on a limited number of locally available food items. Their staple food is corn gruel or corn tortillas. On ordinary days, they are vegetarians [7-9]. Finally, it is clearly established that serum lipid levels are regulated by multiple environmental and genetic factors, and their interactions [7-12]. Although we have detected the interactions of ten SNPs and overweight/obesity on serum lipid levels in this study, there are still many unmeasured environmental and genetic factors and their interactions. Thus, the interactions of gene-gene, gene-environment, and environmentenvironment on serum lipid levels remain to be determined. As a matter of fact, the interrelationship of SNPs and overweight/obesity on serum lipid levels is extremely complex, and was overlooked. For example, obesity-related genes play a role in the central regulation of energy balance, but some of the genes have also a role in the adipose tissue itself [71]. Uncoupling protein 2 gene polymorphisms are associated with obesity in some Asian populations [72]. Reduction in serum IL-18 levels across increasing numbers of +183 G-alleles (rs 5744292) is especially apparent in patient with diabetes type 2 and metabolic syndrome, suggesting a beneficial GG genotype in relation to cardiovascular outcome in these patients [73]. The impact of proteasome modulator 9 (PSMD9) gene within the chromosome 12q24 locus on hypercholesterolemia and contribution to cardio- and cerebrovascular events and inflammation may be high $[74,75]$.

\section{Conclusion}

Several SNPs in normal weight and overweight/obese subjects were found to be associated with serum lipid levels in the Guangxi Bai Ku Yao population. The interactions of ABCA-1, LIPC, LIPG, MTHFR, MYLIP, PCSK9, PPARD, and SCARB1 genotypes and overweight/obesity on serum lipid levels were detected. These results suggest that the differences in serum lipid levels between normal weight and overweight/obese subjects might partly result from different interactions of several SNPs and overweight/obesity. The observed associations and interactions between these SNPs and serum lipid parameters in this isolated ethnic subgroup may also be the major characteristics of these conditions in the other ethnic groups, especially in the minorities. However, large studies of populations with different ethnic origins are required to confirm these observations.

\footnotetext{
Abbreviations

ABCA-1: ATP-binding cassette transporter A1; ACAT-1: Acyl-CoA:cholesterol acyltransferase-1; ANCOVA: Analysis of covariance; Apo: Apolipoprotein; BMI: Body mass index; CAD: Coronary artery disease; DNA: Deoxyribonucleic acid; HDL-C: High-density lipoprotein cholesterol; LDL-C: Low-density lipoprotein cholesterol; LDL-R: Low density lipoprotein receptor; LIPC: Hepatic lipase gene; LIPG: Endothelial lipase gene; LPL: Lipoprotein lipase; MTHFR: Methylenetetrahydrofolate reductase; MYLIP: The E3 ubiquitin
}

ligase myosin regulatory light chain-interacting proteinPCR, Polymerase chain reaction; PCSK9: Proprotein convertase subtilisin-like kexin type 9;

PPARD: Peroxisome proliferator-activated receptor delta; RFLP: Restriction fragment length polymorphism; SCARB1: Scavenger receptor class B type 1; SNPs: Single nucleotide polymorphisms; TC: Total cholesterol; TG: Triglyceride; VLDL: Very low density lipoprotein; WHO: World Health Organization.

\section{Competing interests}

The authors declare that they have no competing interests.

\section{Authors' contributions}

RXY conceived the study, participated in the design, carried out the epidemiological survey, collected the samples, performed statistical analyses, and drafted the manuscript. DFW, LM, LHHA, XLC, TTY, XJL, WYL, LZ, and ML participated epidemiological survey and undertook genotyping. DFW also helped to perform statistical analyses. All authors read and approved the final manuscript.

\section{Acknowledgements}

This work was supported by the National Natural Science Foundation of China (No. 30660061).

\section{Author details}

'Department of Cardiology, Institute of Cardiovascular Diseases, the First Affiliated Hospital, Guangxi Medical University, 22 Shuangyong Road, Nanning, Guangxi 530021, People's Republic of China. ${ }^{2}$ Department of Cardiology, The Third Affiliated Hospital, Guangxi Medical University, Nanning, Guangxi, People's Republic of China. ${ }^{3}$ Department of Cardiology, The People's Hospital of Guilin, Guilin, Guangxi, People's Republic of China. ${ }^{4}$ Department of Internal Medicine, Worker's Hospital of Guangxi Liuzhou Iron and Steel (Group) Company, Liuzhou, Guangxi, People's Republic of China.

Received: 5 October 2012 Accepted: 6 October 2012

Published: 8 October 2012

\section{References}

1. Shekelle RB, Shryock AM, Paul O, Lepper M, Stamler J, Liu S, Raynor WJ Jr: Diet, serum cholesterol, and death from coronary heart disease. The Western Electric study. N Engl J Med 1981, 304:65-70.

2. Austin MA: Plasma triglyceride as a risk factor for coronary heart disease. The epidemiologic evidence and beyond. Am J Epidemiol 1989, 129:249-259.

3. National Cholesterol Education Program (NCEP) Expert Panel on Detectionm, Evaluation, and Treatment of High Blood Cholesterol in Adults (Adult Treatment Panel III): Third Report of the National Cholesterol Education Program (NCEP) Expert Panel on Detection, Evaluation, and Treatment of High Blood Cholesterol in Adults (Adult Treatment Panel III) final report. Circulation 2002, 106:3143-3421.

4. Kwiterovich PO Jr, Coresh J, Smith HH, Bachorik PS, Derby CA, Pearson TA: Comparison of the plasma levels of apolipoproteins $B$ and $A-1$, and other risk factors in men and women with premature coronary artery disease. Am J Cardiol 1992, 69:1015-1021.

5. Hokanson JE, Austin MA: Plasma triglyceride level is a risk factor for cardiovascular disease independent of high-density lipoprotein cholesterol level: a meta-analysis of population-based prospective studies. J Cardiovasc Risk 1996, 3:213-319.

6. Stamler J, Daviglus ML, Garside DB, Dyer AR, Greenland P, Neaton JD: Relationship of baseline serum cholesterol levels in 3 large cohorts of younger men to long-term coronary, cardiovascular, and all-cause mortality and to longevity. JAMA 2000, 284:311-318.

7. Ruixing Y, Qiming F, Dezhai Y, Shuquan L, Weixiong L, Shangling P, Hai W, Yongzhong $Y$, Feng $\mathrm{H}$, Shuming $\mathrm{Q}$ : Comparison of demography, diet, lifestyle, and serum lipid levels between the Guangxi Bai Ku Yao and Han populations. J Lipid Res 2007, 48:2673-2681.

8. Ruixing Y, Shangling P, Hong C, Hanjun Y, Hai W, Yuming C, Jinzhen W, Feng $H$, Meng L, Muyan L: Diet, alcohol consumption, and serum lipid levels of the middle-aged and elderly in the Guangxi Bai Ku Yao and Han populations. Alcohol 2008, 42:219-229.

9. Ruixing $Y$, Dezhai $Y$, Shuquan L, Yuming $C$, Hanjun $Y$, Qiming F, Shangling $P$, Weixiong $L$, Jing $T$, Yiyang $L$ : Hyperlipidaemia and its risk factors in the 
Guangxi Bai Ku Yao and Han populations. Public Health Nutr 2009, 12:816-824.

10. Ruixing Y, Yiyang L, Meng L, Kela L, Xingjiang L, Lin Z, Wanying L, Jinzhen W, Dezhai $Y$, Weixiong L: Interactions of the apolipoprotein C-III 3238C >G polymorphism and alcohol consumption on serum triglyceride levels. Lipids Health Dis 2010, 9:86

11. Zhou Y, Yin R, Deng Y, Li Y, Wu J: Interactions between alcohol intake and the polymorphism of rs708272 on serum high-density lipoprotein cholesterol levels in the Guangxi Hei Yi Zhuang population. Alcohol 2008, 42:583-591.

12. Yin RX, Li YY, Liu WY, Zhang L, Wu JZ: Interactions of the apolipoprotein A5 gene polymorphisms and alcohol consumption on serum lipid levels. PLoS One 2011, 6:e17954.

13. Denke MA, Sempos CT, Grundy SM: Excess body weight: an underrecognized contributor to dyslipidemia in white American women. Arch Intern Med 1994, 154:401-410.

14. Zhou BF, Cooperative Meta-Analysis Group of the Working Group on Obesity in China: Predictive values of body mass index and waist circumference for risk factors of certain related diseases in Chinese adults-study on optimal cut-off points of body mass index and waist circumference in Chinese adults. Biomed Environ Sci 2002, 15:83-96.

15. Kawada T: Body mass index is a good predictor of hypertension and hyperlipidemia in a rural Japanese population. Int $J$ Obes Relat Metab Disord 2002, 26:725-729.

16. Denke MA: Connections between obesity and dyslipidaemia. Curr Opinion Lipidol 2001, 12:625-628.

17. Kopelman PG: Obesity as a medical problem. Nature 2000, 404:635-643.

18. James PT: Obesity: the worldwide epidemic. Clin Dermatol 2004, 22:276-280

19. Cheung $C Y$, Tso AW, Cheung BM, Xu A, Ong KL, Fong CH, Wat NM, Janus $E D$, Sham PC, Lam KS: Obesity susceptibility genetic variants identified from recent genome-wide association studies: implications in a chinese population. J Clin Endocrinol Metab 2010, 95:1395-1403.

20. Ogden CL, Carroll MD, Curtin LR, McDowell MA, Tabak CJ, Flegal KM: Prevalence of overweight and obesity in the United States, 1999-2004. JAMA 2006, 295:1549-1555.

21. Flegal KM, Carroll MD, Ogden CL, Curtin LR: Prevalence and trends in obesity among U.S. adults, 1999-2008. JAMA 2010, 303:235-241.

22. Reynolds K, Gu D, Whelton PK, Wu X, Duan X, Mo J, He J, InterASIA Collaborative Group: Prevalence and risk factors of overweight and obesity in China. Obesity (Silver Spring) 2007, 15:10-18.

23. Teslovich TM, Musunuru K, Smith AV, Edmondson AC, Stylianou IM, Koseki M, Pirruccello JP, Ripatti S, Chasman DI, Willer CJ, Johansen CT, Fouchier SW, Isaacs A, Peloso GM, Barbalic M, Ricketts SL, Bis JC, Aulchenko YS, Thorleifsson G, Feitosa MF, Chambers J, Orho-Melander M, Melander O, Johnson T, Li X, Guo X, Li M, Shin Cho Y, Jin Go M, Jin Kim Y, et al: Biological, clinical and population relevance of 95 loci for blood lipids. Nature 2010, 466:707-713.

24. Aulchenko YS, Ripatti S, Lindqvist I, Boomsma D, Heid IM, Pramstaller PP, Penninx BW, Janssens AC, Wilson JF, Spector T, Martin NG, Pedersen NL, Kyvik KO, Kaprio J, Hofman A, Freimer NB, Jarvelin MR, Gyllensten U, Campbell H, Rudan I, Johansson A, Marroni F, Hayward C, Vitart V, Jonasson I, Pattaro C, Wright A, Hastie N, Pichler I, Hicks AA, et al: Loci influencing lipid levels and coronary heart disease risk in 16 European population cohorts. Nat Genet 2009, 41:47-55.

25. Kathiresan S, Willer CJ, Peloso GM, Demissie S, Musunuru K, Schadt EE, Kaplan L, Bennett D, Li Y, Tanaka T, Voight BF, Bonnycastle LL, Jackson AU, Crawford G, Surti A, Guiducci C, Burtt NP, Parish S, Clarke R, Zelenika D, Kubalanza KA, Morken MA, Scott LJ, Stringham HM, Galan P, Swift AJ, Kuusisto J, Bergman RN, Sundvall J, Laakso M, et al: Common variants at 30 loci contribute to polygenic dyslipidemia. Nat Genet 2009, 41:56-65.

26. Dumitrescu L, Carty CL, Taylor K, Schumacher FR, Hindorff LA, Ambite JL, Anderson G, Best LG, Brown-Gentry K, Bůžková P, Carlson CS, Cochran B, Cole SA, Devereux RB, Duggan D, Eaton CB, Fornage M, Franceschini N, Haessler J, Howard BV, Johnson KC, Laston S, Kolonel LN, Lee ET, MacCluer JW, Manolio TA, Pendergrass SA, Quibrera M, Shohet RV, Wilkens LR, et al: Genetic determinants of lipid traits in diverse populations from the population architecture using genomics and epidemiology (PAGE) study. PLoS Genet 2011, 7:e1002138.
27. Cao XL, Yin RX, Wu DF, Miao L, Aung LH, Hu XJ, Li Q, Yan TT, Lin WX, Pan SL: Genetic variant of V825I in the ATP-binding cassette transporter A1 gene and serum lipid levels in the Guangxi Bai Ku Yao and Han populations. Lipids Health Dis 2011, 10:14.

28. Wu DF, Yin RX, Aung LH, Hu XJ, Cao XL, Miao L, Li Q, Yan TT, Wu JZ, Pan SL: Polymorphism of rs1044925 in the acyl-CoA:cholesterol acyltransferase-1 gene and serum lipid levels in the Guangxi Bai Ku Yao and Han populations. Lipids Health Dis 2010, 9:139.

29. Long XJ, Yin RX, Li KL, Liu WY, Zhang L, Cao XL, Miao L, Wu DF, Htet Aung $\mathrm{LH}, \mathrm{Hu} X \mathrm{XJ}$ : Low density lipoprotein receptor gene Ava II polymorphism and serum lipid levels in the Guangxi Bai Ku Yao and Han populations. Lipids Health Dis 2011, 10:34.

30. Meng $L$, Ruixing $Y$, Yiyang $L$, Xingjiang $L$, Kela $L$, Wanying $L$, Lin $Z$, Weixiong $L$, Dezhai $Y$, Shangling P: Association of LIPC -250G $>A$ polymorphism and several environmental factors with serum lipid levels in the Guangxi Bai Ku Yao and Han populations. Lipids Health Dis 2010, 9:28.

31. Liu WY, Yin RX, Zhang L, Cao XL, Miao L, Wu DF, Aung LH, Hu XJ, Lin WX, Yang DZ: Association of the LIPG 584C $>$ T polymorphism and serum lipid levels in the Guangxi Bai Ku Yao and Han populations. Lipids Health Dis 2010, 9:110.

32. Zhang L, Yin RX, Liu WY, Miao L, Wu DF, Aung LH, Hu XJ, Cao XL, Wu JZ, Pan SL: Association of methylenetetrahydrofolate reductase C677T polymorphism and serum lipid levels in the Guangxi Bai Ku Yao and Han populations. Lipids Health Dis 2010, 9:123.

33. Aung LH, Yin RX, Miao L, Hu XJ, Yan TT, Cao XL, Wu DF, Li Q, Pan SL, Wu JZ: The proprotein convertase subtilisin/kexin type 9 gene E670G polymorphism and serum lipid levels in the Guangxi Bai Ku Yao and Han populations. Lipids Health Dis 2011, 10:5.

34. Miao L, Yin RX, Wu DF, Cao XL, Li Q, Hu XJ, Yan TT, Aung LH, Yang DZ, Lin WX: Peroxisome proliferator-activated receptor delta $+294 \mathrm{~T}>\mathrm{C}$ polymorphism and serum lipid levels in the Guangxi Bai Ku Yao and Han populations. Lipids Health Dis 2010, 9:145.

35. Wu DF, Yin RX, Hu XJ, Aung LH, Cao XL, Miao L, Li Q, Yan TT, Wu JZ, Pan SL: Association of rs5888 SNP in the scavenger receptor class B type 1 gene and serum lipid levels. Lipids Health Dis 2012, 11:50.

36. Zhou B: Effect of body mass index on all-cause mortality and incidence of cardiovas-cular diseases - report for meta-analysis of prospective studies open optimal cut-off points of body mass index in Chinese adults. Biomed Environ Sci 2002, 15:245-252.

37. Jorgensen ME: Obesity and metabolic correlates among the Inuit and a general Danish population. Int J Circumpolar Health 2004, 63:S77-579.

38. Taskinen MR: Type 2 diabetes as a lipid disorder. Curr Mol Med 2005, 5:297-308.

39. Houston MC, Basile J, Bestermann WH, Egan B, Lackland D, Hawkins RG, Moore MA, Reed J, Rogers P, Wise D, Ferrario CM: Addressing the global cardiovascular risk of hypertension, dyslipidemia, and insulin resistance in the southeastern United States. Am J Med Sci 2005, 329:276-291.

40. Pei D, Kuo SW, Wu DA, Lin TY, Hseih MC, Lee CH, Hsu WL, Chen SP, Sheu WH, Li JC: The relationships between insulin resistance and components of metabolic syndrome in Taiwanese Asians. Int J Clin Pract 2005, 59:1408-1416

41. Zambon A, Deeb SS, Hokanson JE, Brown BG, Brunzell JD: Common variants in the promoter of the hepatic lipase gene are associated with lower levels of hepatic lipase activity, buoyant LDL, and higher HDL2 cholesterol. Arterioscler Thromb Vasc Biol 1998, 18:1723-1729.

42. Vega GL, Clark LT, Tang A, Marcovina S, Grundy SM, Cohen JC: Hepatic lipase activity is lower in African American men than in white American men: effects of 5/ flanking polymorphism in the hepatic lipase gene (LIPC). J Lipid Res 1998, 39:228-232.

43. de Andrade FM, Silveira FR, Arsand M, Antunes AL, Torres MR, Zago AJ, Callegari-Jaques SM, Hutz MH: Association between -250G/A polymorphism of the hepatic lipase gene promoter and coronary artery disease and HDL-C levels in a Southern Brazilian population. Clin Genet 2004, 65:390-395.

44. Ko YL, Hsu LA, Hsu KH, Ko YH, Lee YS: The interactive effects of hepatic lipase gene promoter polymorphisms with sex and obesity on highdensity-lipoprotein cholesterol levels in Taiwanese-Chinese. Atherosclerosis 2004, 172:135-142

45. Huang CC, Fornage M, Lloyd-Jones DM, Wei GS, Boerwinkle E, Liu K: Longitudinal association of PCSK9 sequence variations with low-density 
lipoprotein cholesterol levels: the Coronary Artery Risk Development in Young Adults Study. Circ Cardiovasc Genet 2009, 2:354-361.

46. Kotowski IK, Pertsemlidis A, Luke A, Cooper RS, Vega GL, Cohen JC, Hobbs HH: A spectrum of PCSK9 alleles contributes to plasma levels of lowdensity lipoprotein cholesterol. Am J Hum Genet 2006, 78:410-422.

47. Evans D, Beil FU: The E670G SNP in the PCSK9 gene is associated with polygenic hypercholesterolemia in men but not in women. BMC Med Genet 2006, 7:66

48. Chen SN, Ballantyne CM, Gotto AM Jr, Tan Y, Willerson JT, Marian AJ: A common PCSK9 haplotype, encompassing the E670G coding single nucleotide polymorphism, is a novel genetic marker for plasma lowdensity lipoprotein cholesterol levels and severity of coronary atherosclerosis. J Am Coll Cardiol 2005, 45:1611-1619.

49. Hsu LA, Teng MS, Ko YL, Chang CJ, Wu S, Wang CL, Hu CF: The PCSK9 gene E670G polymorphism affects low-density lipoprotein cholesterol levels but is not a risk factor for coronary artery disease in ethnic Chinese in Taiwan. Clin Chem Lab Med 2009, 47:154-158.

50. deLemos AS, Wolfe ML, Long CJ, Sivapackianathan R, Rader DJ: Identification of genetic variants in endothelial lipase in persons with elevated high-density lipoprotein cholesterol. Circulation 2002. 106:1321-1326.

51. Ma K, Cilingiroglu M, Otvos JD, Ballantyne CM, Marian AJ, Chan L: Endothelial lipase is a major genetic determinant for high-density lipoprotein concentration, structure, and metabolism. Proc Natl Acad Sci USA 2003, 100:2748-2753.

52. Shimizu M, Kanazawa K, Hirata K, Ishida T, Hiraoka E, Matsuda Y, Iwai C Miyamoto Y, Hashimoto M, Kajiya T, Akita H, Yokoyama M: Endothelial lipase gene polymorphism is associated with acute myocardial infarction, independently of high-density lipoprotein-cholesterol levels. Circ J 2007, 71:842-846.

53. Yamakawa-Kobayashi K, Yanagi H, Endo K, Arinami T, Hamaguchi H: Relationship between serum HDL-C levels and common genetic variants of the endothelial lipase gene in Japanese school-aged children. Hum Genet 2003, 113:311-315.

54. Huang Y, Wu Y, Liu R, Fan P, Zhang J, Wang F, Luo X, Liu Y, Liu B, Bai H: Differential effect of ATP binding cassette transporter A1 R219K and cholesteryl ester transfer protein TaqlB genotypes on HDL-C levels in overweight/obese and non-obese Chinese subjects. Acta Cardiol 2011 66:231-237

55. Acuña-Alonzo V, Flores-Dorantes T, Kruit JK, Villarreal-Molina T, ArellanoCampos O, Hünemeier T, Moreno-Estrada A, Ortiz-López MG, VillamilRamírez H, León-Mimila P, Villalobos-Comparan M, Jacobo-Albavera L, Ramírez-Jiménez S, Sikora M, Zhang LH, Pape TD, Granados-Silvestre Mde A, Montufar-Robles I, Tito-Alvarez AM, Zurita-Salinas C, Bustos-Arriaga J, Cedillo-Barrón L, Gómez-Trejo C, Barquera-Lozano R, Vieira-Filho JP, Granados J, Romero-Hidalgo S, Huertas-Vázquez A, González-Martín A, Gorostiza A, et al: A functional ABCA1 gene variant is associated with low HDL-cholesterol levels and shows evidence of positive selection in Native Americans. Hum Mol Genet 2010, 19:2877-2885.

56. Kitjaroentham A, Hananantachai H, Tungtrongchitr A, Pooudong S, Tungtrongchitr R: R219K polymorphism of ATP binding cassette transporter A1 related with low HDL in overweight/obese Thai males. Arch Med Res 2007, 38:834-838

57. Morris BJ, Zee RY, Robinson BG: Significant relationships of plasma lipids and body mass index with polymorphisms at the linked low-densitylipoprotein receptor gene and insulin receptor gene loci (19p13.2) in essential hypertensive patients. Clin Sci (Lond) 1994 86:583-592.

58. Zee RY, Schrader AP, Robinson BG, Griffiths LR, Morris BJ: Association of Hincll RFLP of low density lipoprotein receptor gene with obesity in essential hypertensives. Clin Genet 1995, 47:118-121.

59. Griffiths LR, Nyholt DR, Curtain RP, Gaffney PT, Morris BJ: Cross-sectional study of a microsatellite marker in the low density lipoprotein receptor gene in obese normotensives. Clin Exp Pharmacol Physiol 1995, 22:496-498

60. Rutherford S, Nyholt DR, Curtain RP, Quinlan SR, Gaffney PT, Morris BJ, Griffiths LR: Association of a low density lipoprotein receptor microsatellite variant with obesity. Int J Obes Relat Metab Disord 1997, 21:1032-1037
61. Lunegova OS, Kerimkulova AS, Turdakmatov NB, Sovkhozova NA, Nabiev MP, Gotfrid II, Mirrakhimov AÉ, Aldasheva NM, Kheler E, Aldashev AA, Mirrakhimov ÉM: Association of C677T gene polymorphism of methylenetetrahydrofolate reductase with insulin resistance among Kirghizes. Kardiologiia 2011, 51:58-62.

62. Frelut ML, Nicolas JP, Guilland JC, de Courcy GP: Methylenetetrahydrofolate reductase 677 C>T polymorphism: a link between birth weight and insulin resistance in obese adolescents. Int $\mathrm{J}$ Pediatr Obes 2011, 6:e312-e317.

63. Burch LR, Donnelly LA, Doney AS, Brady J, Tommasi AM, Whitley AL, Goddard C, Morris AD, Hansen MK, Palmer CN: Peroxisome proliferatoractivated receptor-delta genotype influences metabolic phenotype and may influence lipid response to statin therapy in humans: a genetics of diabetes audit and research Tayside study. J Clin Endocrinol Metab 2010, 95:1830-1837

64. Yan ZC, Shen CY, Zhong J, Wang L, Ni YX, Nie H, Zhu ZM: PPARdelta + 294T/C gene polymorphism related to plasma lipid, obesity and left ventricular hypertrophy in subjects with metabolic syndrome. Zhonghua Xin Xue Guan Bing Za Zhi 2005, 33:529-533.

65. Aberle J, Hopfer I, Beil FU, Seedorf U: Association of peroxisome proliferator-activated receptor delta $+294 \mathrm{~T} / \mathrm{C}$ with body mass index and interaction with peroxisome proliferator-activated receptor alpha L162V. Int J Obes (Lond) 2006, 30:1709-1713.

66. Talmud PJ, Berglund L, Hawe EM, Waterworth DM, Isasi CR, Deckelbaum RE, Starc T, Ginsberg HN, Humphries SE, Shea S: Age-related effects of genetic variation on lipid levels: The Columbia University BioMarkers Study. Pediatrics 2001, 108:E50.

67. Nie L, Wang J, Clark LT, Tang A, Vega GL, Grundy SM, Cohen JC: Body mass index and hepatic lipase gene (LIPC) polymorphism jointly influence postheparin plasma hepatic lipase activity. J Lipid Res 1998, 39:1127-1130.

68. Deeb SS, Zambon A, Carr MC, Ayyobi AF, Brunzell JD: Hepatic lipase and dyslipidemia: interactions among genetic variants, obesity, gender, and diet. J Lipid Res 2003, 44:1279-1286.

69. St-Pierre J, Miller-Felix I, Paradis ME, Bergeron J, Lamarche B, Després JP, Gaudet D, Vohl MC: Visceral obesity attenuates the effect of the hepatic lipase -514C $>\mathrm{T}$ polymorphism on plasma HDL-cholesterol levels in French-Canadian men. Mol Genet Metab 2003, 78:31-36.

70. Swarbrick MM, Chapman CM, McQuillan BM, Hung J, Thompson PL, Beilby JP: A Pro12Ala polymorphism in the human peroxisome proliferatoractivated receptor-gamma 2 is associated with combined hyperlipidaemia in obesity. Eur J Endocrinol 2001, 144:277-282.

71. Schmid PM, Heid I, Buechler C, Steege A, Resch M, Birner C, Endemann DH, Riegger GA, Luchner A: Expression of fourteen novel obesity-related genes in zucker diabetic fatty rats. Cardiovasc Diabetol 2012, 11:48.

72. Oktavianthi S, Trimarsanto H, Febinia CA, Suastika K, Saraswati MR, Dwipayana P, Arindrarto W, Sudoyo H, Malik SG: Uncoupling protein 2 gene polymorphisms are associated with obesity. Cardiovasc Diabetol 2012, 11:41.

73. Opstad TB, Pettersen AÅ, Arnesen H, Seljeflot I: Circulating levels of IL-18 are significantly influenced by the IL-18 $+183 \mathrm{~A} / \mathrm{G}$ polymorphism in coronary artery disease patients with diabetes type 2 and the metabolic syndrome: an observational study. Cardiovasc Diabetol 2011, 10:110.

74. Gragnoli C: Hypercholesterolemia and a candidate gene within the 12q24 locus. Cardiovasc Diabetol 2011, 10:38.

75. Gragnoli C: Proteasome modulator 9 is linked to microvascular pathology of T2D. J Cell Physiol 2012, cbt:3116-3118.

doi:10.1186/1475-2840-11-123

Cite this article as: Yin et al:: Several genetic polymorphisms interact with overweight/obesity to influence serum lipid levels. Cardiovascular Diabetology 2012 11:123. 